\title{
The antimicrobial action of polyaniline involves production of oxidative stress while functionalisation of polyaniline introduces additional mechanisms
}

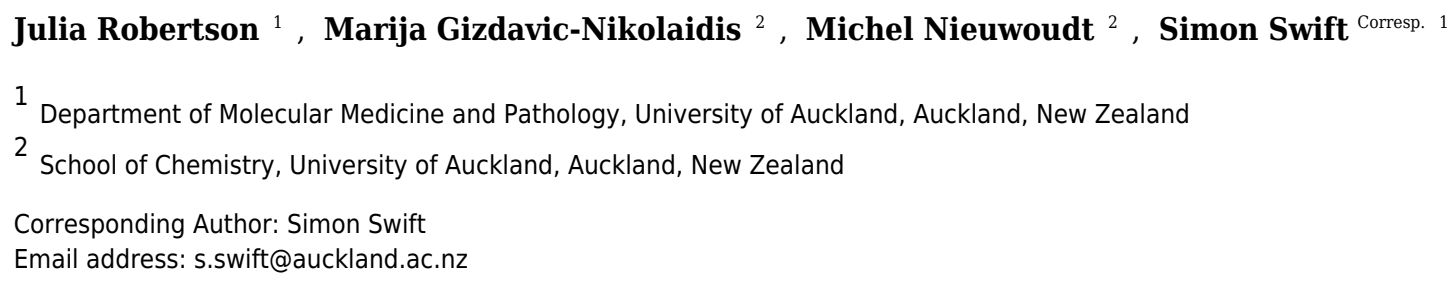

Polyaniline (PANI) and functionalised polyanilines (fPANI) are novel antimicrobial agents whose mechanism of action was investigated. Escherichia coli single gene deletion mutants revealed that the antimicrobial mechanism of PANI likely involves production of hydrogen peroxide while homopolymer poly(3-aminobenzoic acid), P3ABA, used as an example of a fPANI, disrupts metabolic and respiratory machinery, by targeting ATP synthase and causes acid stress. PANI was more active against E. coli in aerobic, compared to anaerobic, conditions, while this was apparent for P3ABA only in rich media. Greater activity in aerobic conditions suggests involvement of reactive oxygen species. P3ABA treatment causes an increase in intracellular free iron, which is linked to perturbation of metabolic enzymes and could promote reactive oxygen species production. Addition of exogenous catalase protected E. coli from PANI antimicrobial action; however, this was not apparent for P3ABA treated cells. The results presented suggest that PANI induces production of hydrogen peroxide, which can promote formation of hydroxyl radicals causing biomolecule damage and potentially cell death. P3ABA is thought to act as an uncoupler by targeting ATP synthase resulting in a futile cycle, which precipitates dysregulation of iron homeostasis, oxidative stress, acid stress, and potentially the fatal loss of proton motive force. 


\section{The antimicrobial action of polyaniline involves} production of oxidative stress while

\section{functionalisation of polyaniline introduces additional mechanisms}

Running title: Mode of action for PANI and fPANI

Julia Robertson $^{1}$, Marija Gizdavic-Nikolaidis ${ }^{2}$, Michel Nieuwoudt ${ }^{2}$ and Simon Swift ${ }^{1}$

${ }^{1}$ Department of Molecular Medicine and Pathology, and ${ }^{2}$ School of Chemical Sciences, University of Auckland, Auckland, New Zealand

Corresponding Author: Simon Swift, Department of Molecular Medicine and Pathology, Faculty of Medical and Health Sciences, University of Auckland, Private Bag 92019, Auckland, New Zealand. Ph +64 93737599 ext 86273. Email s.swift@auckland.ac.nz. 


\section{Abstract}

2 Polyaniline (PANI) and functionalised polyanilines (fPANI) are novel antimicrobial agents

3 whose mechanism of action was investigated. Escherichia coli single gene deletion mutants

4 revealed that the antimicrobial mechanism of PANI likely involves production of hydrogen

5 peroxide while homopolymer poly(3-aminobenzoic acid), P3ABA, used as an example of a

6 fPANI, disrupts metabolic and respiratory machinery, by targeting ATP synthase and causes acid

7 stress. PANI was more active against $E$. coli in aerobic, compared to anaerobic, conditions, while

8 this was apparent for P3ABA only in rich media. Greater activity in aerobic conditions suggests

9 involvement of reactive oxygen species. P3ABA treatment causes an increase in intracellular

10 free iron, which is linked to perturbation of metabolic enzymes and could promote reactive

11 oxygen species production. Addition of exogenous catalase protected E. coli from PANI

12 antimicrobial action; however, this was not apparent for P3ABA treated cells. The results

13 presented suggest that PANI induces production of hydrogen peroxide, which can promote

14 formation of hydroxyl radicals causing biomolecule damage and potentially cell death. P3ABA

15 is thought to act as an uncoupler by targeting ATP synthase resulting in a futile cycle, which

16 precipitates dysregulation of iron homeostasis, oxidative stress, acid stress, and potentially the

17 fatal loss of proton motive force. 
19

20

21

22

23

24

25

26

27

28

29

30

\section{Introduction}

Conducting polymers (CPs) are a class of polymeric materials that have electronic and ionic conductivity (Macdiarmid, 2002; Ravichandran et al., 2010). Polyaniline (PANI) and its derivatives comprise an important and widely studied class of conducting polymers (Macdiarmid, 2002; Dhand et al., 2011). Polyanilines are deemed to be derived from a polymer consisting of varying relative amounts of reduced and/or oxidised aniline subunits (Fig. 1A) (Macdiarmid, 2002; Stejskal, Sapurina \& Trchová, 2010). The emeraldine state ('half-oxidised') has the greatest stability at room temperature. Application of a dopant ion to emeraldine base (EB) imparts conductivity and the resulting electrically conductive doped form, emeraldine salt (ES), is considered the most applicable form of PANI (Ravichandran et al., 2010; Dhand et al., 2011).

The utilisation of PANI is restricted by its insolubility in common solvents (Genies et al., 1990; Gizdavic-Nikolaidis et al., 2011). Functionalised polyanilines (fPANI) are synthesised from functionalised aniline monomers, and exhibit improved solubility and processability. (Su \& Kuramoto, 2000; Gizdavic-Nikolaidis et al., 2010b,a; Ravichandran et al., 2010). A promising fPANI candidate is poly(3-aminobenzoic acid), P3ABA (Fig. 1B) (Salavagione et al., 2004; Stejskal, Sapurina \& Trchová, 2010; Gizdavic-Nikolaidis et al., 2011).

PANI and fPANI are novel antimicrobial agents that are active against a broad range of bacteria including Escherichia coli, Staphylococcus aureus, Pseudomonas aeruginosa, Enterococcus faecalis, and Campylobacter jejuni (Shi et al., 2006; Gizdavic-Nikolaidis et al., 2011; Prasad et al., 2012; Kucekova et al., 2013; Dhivya, Vandarkuzhali \& Radha, 2014). PANI and fPANI have potential to be incorporated into surfaces or used as surface coatings for infection control and food safety applications (Robertson, Gizdavic-Nikolaidis \& Swift, 2018). The mechanistic basis of antimicrobial activity is hypothesised to involve electrical conductivity, which can mediate contact with the negatively charged bacterial cell surface through electrostatic adherence (Seshadri \& Bhat, 2005; Shi et al., 2006; Gizdavic-Nikolaidis et al., 2011). Determination of the mode of action of an antimicrobial agent is of value (Kohanski, Dwyer \& Collins, 2010; Green, Fulghum \& Nordhaus, 2011). Knowledge of mechanism of action aids in understanding and interpreting the antimicrobial activity in experimental assays (Green, Fulghum \& Nordhaus, 2011). Rational improvement of an antimicrobial agent, such as via functionalisation of PANI, is 
reliant on elucidation of antimicrobial mechanism (Brazas \& Hancock, 2005; Kohanski, Dwyer \& Collins, 2010; Grass, Rensing \& Solioz, 2011). The possibility of the emergence and spread of resistant organisms may also be informed from the mode of action of an antimicrobial agent (Brazas \& Hancock, 2005; Grass, Rensing \& Solioz, 2011).

The antimicrobial mechanism of an fPANI, a homopolymer of sulfanilic acid $\left(\mathrm{PSO}_{3} \mathrm{H}\right)$, has been previously examined. Initial hypotheses pertaining to fPANI action were generated following analysis of the results of a transcriptomic analysis of E. coli MG1655 sub-lethally challenged with $\mathrm{PSO}_{3} \mathrm{H}$ (Gizdavic-Nikolaidis et al., 2011). The interpretation of the transcriptomic analysis assumes that for the challenged cells upregulated genes are involved in the responses to any stresses experienced; whereas genes downregulated are possible targets. The $\mathrm{PSO}_{3} \mathrm{H}$ challenged E. coli demonstrated upregulation of stress response genes involved in defence against oxidative and periplasmic stress as well as genes associated with iron homeostasis (Gizdavic-Nikolaidis et al., 2011). Expression of some genes in the OxyR regulon (Anjem, Varghese \& Imlay, 2009), which is activated by hydrogen peroxide $\left(\mathrm{H}_{2} \mathrm{O}_{2}\right)$ stress, were increased, such as $\operatorname{tr} x C$, grx A, $m n t H$, and $s u f B$. The protein products of these genes act to restore redox balance (Trx2, Grx1) and reactivate or repair oxidatively damaged enzymes (MntH and SufB) (Anjem, Varghese \& Imlay, 2009). A few genes in the SoxRS regulon (Gu \& Imlay, 2011), which responds to superoxide-based stress, were also upregulated, such as $\operatorname{sox} R$, soxS, and fumC. Periplasmic stress response genes included spy, asr, and cpxP, which encode proteins that act to reduce protein misfolding and aggregation (Seputiene et al., 2003; Raivio, Leblanc \& Price, 2013). Upregulated genes involved in iron homeostasis (Liu, Bauer \& Imlay, 2011) included sufC and fes. The sufC gene is a member of the SUF pathway and encodes an ATPase that facilitates transfer of nascent iron sulphur $(\mathrm{FeS})$ clusters to apo-protein substrates or acts as a carrier protein during repair of oxidised FeS clusters (Bandyopadhyay, Chandramouli \& Johnson, 2008; Mettert \& Kiley, 2015). The fes gene encodes an esterase enzyme that mediates release of iron from the enterobactin-iron complex during iron import (Andrews, Robinson \& Rodríguez-Quiñones, 2003; Adler et al., 2014).

Downregulation of genes was also identified in the transcriptomic analysis (Gizdavic-Nikolaidis et al., 2011). These genes encoded proteins involved in central metabolism and energy generation including tricarboxylic acid (TCA) cycle genes, such as $s d h B$ and ace $A$ (MartínezGómez et al., 2012). The gene $s d h B$ encodes the b subunit of succinate dehydrogenase (SDH) 
80 (Cheng et al., 2006; Tran et al., 2006). SDH oxidises succinate generating fumarate in the TCA

81 cycle. Electrons from this oxidation are shuttled into the electron transport chain (ETC), providing a functional link between the TCA cycle and the ETC (Cheng et al., 2006; Tran et al., 2006). The SdhB subunit contains an $[4 \mathrm{Fe}-4 \mathrm{~S}]^{2+}$ cluster, which is susceptible to oxidation by $\mathrm{H}_{2} \mathrm{O}_{2}$ resulting in dissociation of an iron atom and loss of enzyme activity (Tran et al., 2006; Imlay, 2013). Isocitrate lyase, encoded by the ace $A$ gene, is a glyoxylate shunt enzyme that cleaves isocitrate to generate succinate and glyoxylate (Blankenhorn, Phillips \& Slonczewski, 1999; Kim \& Copley, 2007). Isocitrate lyase expression is induced by oxygen (Blankenhorn, Phillips \& Slonczewski, 1999). The transcriptional response of E. coli MG1655 to the fPANI led to the development of several hypotheses pertaining to potential mechanisms of action including induction of oxidative stress, dysregulation of iron homeostasis, targeting of metabolic and respiratory enzymes, and disruption of membrane integrity.

Antimicrobial activity can be influenced by the physical properties of the polymer chain, including chain length and monomer type (Gizdavic-Nikolaidis et al., 2012). Therefore, the antimicrobial mechanisms of PANI or P3ABA may differ from that of $\mathrm{PSO}_{3} \mathrm{H}$ and required separate determination. In this study we characterise the antimicrobial mechanism of the more potent ES forms of PANI and P3ABA (Shi et al., 2006; Gizdavic-Nikolaidis et al., 2011) against E. coli 25922, a standard antibiotic sensitivity testing strain (Wiegand, Hilpert \& Hancock, 2008). Previous work has demonstrated PANI and P3ABA activity against E. coli and Staphylococcus aureus in suspension and when incorporated into surfaces (Robertson, GizdavicNikolaidis \& Swift, 2018). We present evidence that supports an antimicrobial action for PANI that involves production of $\mathrm{H}_{2} \mathrm{O}_{2}$, which can promote formation of hydroxyl radicals causing biomolecule damage and potentially cell death. P3ABA was demonstrated to target ATP synthase, acting as an uncoupler, likely resulting in a futile cycle, which can promote dysregulation of iron homeostasis, oxidative stress, acid stress, and potentially the fatal loss of proton motive force.

\section{Materials \& methods}

\section{Bacterial strains}


108 The antimicrobial mechanism of PANI and P3ABA was initially investigated using E. coli single

109 gene deletion mutants from the Keio collection (Baba et al., 2006; Tamae et al., 2008). The

110 parent strain, E. coli K-12 strain BW25113 (F- $\Delta(\operatorname{araD}-a r a B) 567, \Delta l a c Z 4787(:: r r n B-3), \lambda-$, rph-

111 1, $\Delta(r h a D-r h a B) 568, h s d R 514)$ and a selection of the isogenic E. coli deletion mutants were used

112 in this work. These deletion mutants were E. coli JW3914-1 $\Delta k a t G, E$. coli JW1721-1 $\Delta k a t E, E$.

113 coli JW0598-2 $\Delta a h p C$, E. coli JW3879-1 $\Delta$ sodA, E. coli JW1648-1 $\Delta$ sodB, E. coli JW1638-1

$114 \Delta$ sodC, E. coli JW0669-2 $\Delta$ fur, E. coli JW2566-1 $\Delta \operatorname{trx} C$, E. coli JW0833-1 $\Delta$ grxA, E. coli

115 JW5195-1 $\Delta$ tonB, E. coli JW2514-4 $\Delta i s c S$, E. coli JW0714-1 $\Delta s d h B, E$. coli JW3715-1 $\Delta a t p E$,

116 E. coli JW1732-1 $\Delta s p y$, E. coli JW5826-1 $\Delta a s r$, E. coli JW2669-1 $\Delta r e c A$ and E. coli JW1625-1

117 Dnth.

118 E.coli ATCC 25922 (referred to as E. coli 25922) was selected for further characterisation of the

119 action of PANI and P3ABA because it is a standard antibiotic sensitivity testing strain (Wiegand,

120 Hilpert \& Hancock, 2008). All strains were grown at $37^{\circ} \mathrm{C}$, with shaking at $200 \mathrm{rpm}$ where

121 appropriate.

122 Media and chemicals

123 PANI and P3ABA were synthesised via chemical oxidation of aniline and 3-aminobenzoic acid

124 monomers, respectively (Gizdavic-Nikolaidis et al., 2011). Cell biology reagents were purchased

125 from Sigma-Aldrich. General reagents included sodium chloride, methylene blue, resazurin

126 sodium salt, agar, L-cysteine, glycerol, potassium nitrate, sodium succinate dibasic hexahydrate

127 and $30 \% \mathrm{w} / \mathrm{v} \mathrm{H}_{2} \mathrm{O}_{2}$.

128 Bacteria were cultured in LB broth (BD) or in minimal media. Minimal A medium was used to

129 support growth in a minimal environment providing only essential nutrients. A $5 \times$ minimal A

130 solution was made according to the following: $5 \mathrm{~g}\left(\mathrm{NH}_{4}\right)_{2} \mathrm{SO}_{4}, 22.5 \mathrm{~g} \mathrm{KH}_{2} \mathrm{PO}_{4}, 52.5 \mathrm{~g} \mathrm{~K}_{2} \mathrm{HPO}_{4}$,

$1312.5 \mathrm{~g}$ sodium citrate. $2 \mathrm{H}_{2} \mathrm{O}$. After autoclaving, this solution was diluted to $1 \times$ with sterile water

132 and the following sterile solutions, per litre: $1 \mathrm{ml} 1 \mathrm{M} \mathrm{MgSO}_{4} \cdot 7 \mathrm{H}_{2} \mathrm{O}, 0.1 \mathrm{ml} 0.5 \%$ thiamine plus

133 the carbon source ( $10 \mathrm{ml}$ of $70 \%$ glycerol solution or $10 \mathrm{ml}$ of $40 \%$ succinate solution per litre).

134 A $20 \%$ casamino acid solution was used at $0.1 \%$ in minimal A salts media where needed to

135 overcome growth defects.

136 A $0.2 \mathrm{M}$ deferoxamine mesylate (DF) solution was prepared by adding $131.36 \mathrm{~g}$ of DF per litre

137 to water and adjusting the $\mathrm{pH}$ to 7.4 using $\mathrm{KOH}$. A $20 \mathrm{mM}$ Tris-HCl-10 \% glycerol (pH 7.4) 
138 buffer solution was prepared by adding $2.4 \mathrm{~g}$ Tris ultrapure and $100 \mathrm{ml}$ glycerol per litre of water

139 and adjusting the $\mathrm{pH}$ using concentrated $\mathrm{HCl}$.

\section{Preparation of PANI and P3ABA suspensions}

141 PANI was finely ground using a mortar and pestle. This insoluble powder requires shaking at $142200 \mathrm{rpm}$ to stay in suspension. Reflecting the improved solubility of P3ABA, this polymer was

143 suspended in broth using the QSonica Q700 Sonicator at the following settings: amplitude 30, 144 elapsed time 10 s, repeat $4 \times$.

\section{Sensitivity of $E$. coli deletion mutants to PANI and P3ABA suspensions}

Suspensions of PANI and P3ABA were prepared at $2 \%(\mathrm{w} / \mathrm{v})$ for a final concentration of $1 \%$ in antimicrobial challenges. Turbid cultures of test bacteria (parent strain plus deletion mutant strains) were diluted to $10^{6} \mathrm{CFU} / \mathrm{ml}$ in LB broth or minimal A salts with $0.4 \%$ succinate. The $E$. coli deletion mutants missing genes associated with metabolism (E. coli $\Delta i s c S, E$. coli $\Delta$ tonB, and $E$. coli $\Delta s d h B$ ) displayed growth defects in minimal media, which were overcome by supplementing the minimal media with $0.1 \%$ casamino acids for both the mutant strain and the parent strain. E. coli $\triangle a t p E$ was unable to grow in minimal media even with supplementation of casamino acids and therefore was only tested in rich media.

Samples of $500 \mu \mathrm{l}$ of either PANI suspension, P3ABA suspension, and growth media (no antimicrobial control) were inoculated with $500 \mu$ l of diluted culture. The experimental samples were incubated at $37^{\circ} \mathrm{C}$ with $200 \mathrm{rpm}$ agitation. For challenge in rich media, PANI treated cells were rescued at $2 \mathrm{~h}$ and $4 \mathrm{~h}$ while P3ABA treated cells were rescued at $0.5 \mathrm{~h}$ and $1 \mathrm{~h}$ reflecting the difference in activity levels against target bacteria in LB broth. For challenge in minimal media, both PANI and P3ABA treated cells were recovered after $1 \mathrm{~h}$ of incubation. At these time points, an aliquot from each experimental sample was enumerated using the drop plate method on LB agar plates. Following incubation, colonies were counted and CFU/ml was calculated. At least three biological replicates were obtained. Linear regression analysis was used to compare the sensitivity of the parent strain to that of each E. coli deletion mutant for both PANI and P3ABA. Data was graphed in a scatter plot generated with viable cell counts post-treatment $(\mathrm{CFU} / \mathrm{ml})$ represented on the $y$-axis and time $(\mathrm{h})$ represented on the $x$-axis. Linear regression was used to fit a straight line (regression line) 
167 through the data for the categorical factor (bacterial gene mutation) generating the best-fit value 168 of the slope and intercept. An analysis of covariance (ANCOVA) was used to compare the

169

170

171

172

173

174

175

176

177

178

179

180

181

182

183

184

185

186

regression lines from the parent strain and a mutant strain to determine if the effect of bacterial gene mutation on viable cell count post-treatment represented a statistically significant increase or decrease in sensitivity. Significant differences in sensitivity between the parent strain and a mutant strain are represented in Table 1.

\section{Electron paramagnetic resonance (EPR) spectroscopy}

The protocol used was based on the whole cell EPR assay to detect free iron in E. coli (Woodmansee \& Imlay, 2002; Liu \& Imlay, 2013). A turbid culture of E. coli 25922 was diluted 1:100 in $6 \times 200 \mathrm{ml} \mathrm{LB}$ broth aliquots and grown aerobically at $37^{\circ} \mathrm{C}$ until log phase (optical density at $600 \mathrm{~nm}, \mathrm{OD}_{600}$, of 0.4-0.6) was reached. All cultures were centrifuged at 3,000 $\mathrm{xg}$ at 4 ${ }^{\circ} \mathrm{C}$ for 5 min. Two cultures were assigned to P3ABA treatment, to $\mathrm{H}_{2} \mathrm{O}_{2}$ treatment or left untreated as a control. A $5 \%$ P3ABA suspension in LB broth was prepared.

The cultures for P3ABA treatment were resuspended in $8 \mathrm{ml} \mathrm{LB}$ broth, $1 \mathrm{ml} 5 \%$ P3ABA suspension and $1 \mathrm{ml}$ of $0.2 \mathrm{M}$ DF solution. Final concentrations of P3ABA and DF were $0.5 \%$ $(\mathrm{w} / \mathrm{v})$ and $0.02 \mathrm{M}$, respectively. The P3ABA treated cultures were incubated at $37^{\circ} \mathrm{C}$ with shaking for $30 \mathrm{~min}$. The cultures for $\mathrm{H}_{2} \mathrm{O}_{2}$ treatment were resuspended in $8 \mathrm{ml} \mathrm{LB}$ broth, $1 \mathrm{ml}$ $200 \mathrm{mM} \mathrm{H}_{2} \mathrm{O}_{2}$, and $1 \mathrm{ml}$ of $0.2 \mathrm{M} \mathrm{DF}$ solution, and incubated for $5 \mathrm{~min}$. Untreated cultures were resuspended in $9 \mathrm{ml} \mathrm{LB}$ broth and $1 \mathrm{ml}$ of $0.2 \mathrm{M} \mathrm{DF}$ solution, and incubated for $30 \mathrm{~min}$.

All cultures were centrifuged at $3,400 \mathrm{xg}$ at $4{ }^{\circ} \mathrm{C}$ for 5 min twice. They were washed with $10 \mathrm{ml}$ ice cold $20 \mathrm{mM}$ Tris-HCl-10\% glycerol pH 7.4 buffer and finally resuspended in $200 \mu \mathrm{l}$ of buffer. A $200 \mu \mathrm{l}$ aliquot of each cell suspension was added to a $4 \mathrm{~mm}$ quartz tube and frozen in a dry ice-ethanol bath. Samples were stored at $-80^{\circ} \mathrm{C}$ prior to EPR analysis. A $10 \mu \mathrm{l}$ aliquot of each sample was diluted 1:100 in buffer and the $\mathrm{OD}_{600}$ was determined.

The EPR standard was established by dissolving $0.15 \mathrm{~g}$ of anhydrous $\mathrm{Fe}_{2}\left(\mathrm{SO}_{4}\right)_{3}$ in $20 \mathrm{mM}$ TrisHCl-1 mM DF-10 \% glycerol (pH 7.4). The ferric sulfate solution was diluted to a range of concentrations $(6 \mu \mathrm{M}, 17 \mu \mathrm{M}, 36 \mu \mathrm{M}, 76 \mu \mathrm{M}$, and $375 \mu \mathrm{M})$. The absorption coefficient, $\varepsilon_{420}=$ $2.865 \mathrm{mM}^{-1} \mathrm{~cm}^{-1}$, was used precisely quantitate the $\mathrm{Fe}^{3+}$ concentrations using the Beer-Lambert law. The ferric sulfate solutions were loaded into EPR tubes and handled in the same manner as the cultures. 
197 The EPR signals were recorded using the JEOL JES-FA 200 EPR spectrometer. The recording

198 temperature was set at $-196^{\circ} \mathrm{C}$ by liquid nitrogen. The measurement parameters were as follows:

199 magnetic centre field $151.419 \mathrm{mT}$, microwave frequency $9072.85 \mathrm{MHz}$, microwave power 6.0

$200 \mathrm{~mW}$, sweep width $50 \mathrm{mT}$, modulation width $0.35 \mathrm{mT}$, amplitude/gain 200, time constant $0.10 \mathrm{~s}$

201 and scan time two min. EPR spectra were confirmed in two replicate experiments. The spin

202 number of each sample was calculated from the second integral of the recorded EPR spectrum.

203 Data generated from measuring free iron using EPR is presented as a spectrum in which the size

204 of the peak can be used to quantify the concentration of $\mathrm{Fe}^{3+}$ (Cammack \& Cooper, 1993;

205 Woodmansee \& Imlay, 2002). The area under the peak corresponds to the signal intensity

206 (Woodmansee \& Imlay, 2002). A large peak corresponds to a high level of free iron and a small

207 peak corresponds to a normal low level (Woodmansee \& Imlay, 2002). The concentration of iron

$208(\mu \mathrm{M})$ for each sample was determined from iron buffer standard curve (Woodmansee \& Imlay,

209 2002). From the two cultures, the median free iron value for each treatment was calculated. At

210 least three biological replicates were obtained. The Kruskal-Wallis test with Dunn's multiple

211 comparison post-hoc test was used analyse difference between the free iron levels of P3ABA

212 treated, $\mathrm{H}_{2} \mathrm{O}_{2}$ treated, and untreated cells.

213 Assay to determine the activity of PANI and P3ABA suspensions in

214 aerobic and anaerobic conditions against $\boldsymbol{E}$. coli

215 E. coli 25922 was challenged with PANI or P3ABA suspensions in aerobic and anaerobic

216 conditions to determine the minimum inhibitory concentration (MIC) and minimum bactericidal

217 concentration (MBC) (Andrews, 2001; Dwyer et al., 2014). GasPak ${ }^{\mathrm{TM}}$ EZ Small Incubation

218 Containers were used in conjunction with GasPak ${ }^{\mathrm{TM}} \mathrm{EZ}$ Anaerobic Container System sachets to

219 create an anaerobic environment for antimicrobial testing. To prepare the growth media for

220 antimicrobial assays in anaerobic conditions, a $2 \%$ cysteine stock solution was added to liquid

221 growth media to a final concentration of $0.05 \%$ to create a reducing environment with less

222 reactive oxygen species (ROS) present (Park \& Imlay, 2003). The anaerobic environments used

223 in this work were monitored using the redox indicator solutions, $0.0002 \%$ methylene blue and

$2240.0002 \%$ resazurin. These dyes appear blue when oxidised (indicating oxygen is present) and

225 colourless when reduced (indicating oxygen is absent) (Karakashev, Galabova \& Simeonov,

226 2003). 
227 A range of concentrations of PANI and P3ABA in suspension were established. PANI is an 228 insoluble powder that is not suitable for dilution from a stock solution. Each PANI suspension 229 was set up separately by weighing the powder into $5 \mathrm{ml}$ tubes and adding $500 \mu \mathrm{l}$ of broth. A 230 P3ABA stock suspension was established by adding $0.8 \mathrm{~g}$ of P3ABA to $5 \mathrm{ml}$ of broth. The 231 P3ABA stock suspension was diluted to $0.125 \%$ P3ABA using doubling dilution series. The 232 suspensions were established at $2 \times$ the final desired concentration (which was achieved 233 following inoculation with an equal volume). Final concentrations tested were $0.00391 \%-16 \%$ 234 for PANI and $0.015625 \%$ - $8 \%$ for P3ABA. $500 \mu \mathrm{l}$ of each established suspension was 235 aliquoted into a $5 \mathrm{ml}$ tube and $500 \mu \mathrm{l}$ of growth media was aliquoted to set up an untreated 236 control. LB broth was used as a rich media while minimal A salts was used as a minimal media 237 with $0.7 \%$ glycerol or $0.4 \%$ succinate as the carbon source. To support the growth of cells in 238 anaerobic conditions, potassium nitrate was added at $20 \mathrm{mM}$ to the minimal media. Nitrate can 239 act as a terminal electron acceptor in E. coli facilitating anaerobic respiration (Dwyer et al., 240 2014). For treatment in aerobic conditions, no nitrate was present in the growth media.

241 An E. coli 25922 culture, suspensions for anaerobic challenge, media used for preparing the 242 inoculum, and redox indicator tubes were incubated anaerobically at $37^{\circ} \mathrm{C}$ with $200 \mathrm{rpm}$ 243 shaking. Aerobic suspensions and redox indicator tubes were incubated aerobically at $37{ }^{\circ} \mathrm{C}$ with $244200 \mathrm{rpm}$ shaking. Following a $24 \mathrm{~h}$ (for LB broth) or $48 \mathrm{~h}$ (for minimal media) incubation, a 245 turbid anaerobic culture of test bacteria was diluted to $10^{6} \mathrm{CFU} / \mathrm{ml}$ in broth. The inoculum was retrospectively enumerated using the spread plate method.

247 Each aerobic and anaerobic PANI or P3ABA suspension (and the untreated control) was 248 inoculated with $500 \mu \mathrm{l}$ of diluted culture. The experimental samples were incubated aerobically and anaerobically (as appropriate). The MIC was defined as the lowest concentration of PANI or P3ABA that was able to inhibit the visible growth of test bacteria following a $24 \mathrm{~h}$ or $48 \mathrm{~h}$ treatment.

Tubes that were observed by eye to have no visible growth were selected for MBC testing. For this, $20 \mu \mathrm{l}$ of the experimental sample was spread onto $6 \mathrm{LB}$ agar plates. The spread plates were incubated at $37^{\circ} \mathrm{C}$ for $16 \mathrm{~h}$ and growth on these plates was determined. When countable colonies were present, the CFU/ml of the sample was calculated. Bactericidal activity was defined as 99.9 
257 concentration of PANI or P3ABA that prevented the growth of test bacteria following subculture 258 on LB agar plates. At least three biological replicates were obtained for each experiment.

259 The Mann-Whitney test was used to analyse the difference between the aerobic and anaerobic 260 MIC, and the aerobic and anaerobic MBC of PANI and P3ABA against E. coli 25922. A P value 261 of less than 0.05 is taken to signify that the differences between the two groups is true while a $\mathrm{P}$ value of more than 0.05 is taken to indicate that the distribution of data of both groups is the same. The Mann-Whitney test was also used to compare the difference between the influence of the presence of oxygen on the activity of PANI and P3ABA against E. coli 25922.

265

266

267

268

269

270

271

272

273

274

275

276

277

278

279

280

281

282

283

284

285

\section{Catalase protection assay}

Suspensions of PANI and P3ABA in LB broth were prepared to achieve final concentrations of 2 $\%$ and $0.5 \%(\mathrm{w} / \mathrm{v})$, respectively. $\mathrm{A}_{2} \mathrm{O}_{2}$ solution was prepared for a final concentration of 10 $\mathrm{mM}$ in $0.85 \%$ saline. A $500 \mathrm{U} / \mathrm{ml}$ solution of catalase was made in LB broth. A turbid culture of E. coli 25922 was diluted to $10^{6} \mathrm{CFU} / \mathrm{ml}$ in LB broth. $500 \mu 1$ aliquots of diluted culture were challenged with PANI suspension, P3ABA suspension, $\mathrm{H}_{2} \mathrm{O}_{2}$ solution, or LB broth (untreated control) in the presence or absence of exogenous catalase. Experimental samples were incubated at $37^{\circ} \mathrm{C}$ with $200 \mathrm{rpm}$ agitation. PANI treated and P3ABA treated cells were enumerated at $2 \mathrm{~h}$, and $0.5 \mathrm{~h}$ time points, respectively. $\mathrm{H}_{2} \mathrm{O}_{2}$ treated and untreated cells were enumerated at all time points using the drop plate method. At least three biological replicates were obtained. A repeated measures ANOVA was used to analyse the difference in cell viability of PANI treated, P3ABA treated, and $\mathrm{H}_{2} \mathrm{O}_{2}$ treated cells in the presence and absence of exogenous catalase.

\section{Statistical analysis}

Statistical analysis for all experiments was performed using GraphPad Prism software version 6 (GraphPad Software, Inc.). A P value less than 0.05 was considered to represent statistical significance.

\section{Sensitivity of $E$. coli deletion mutants to PANI and P3ABA suspensions}

Linear regression analysis was used to compare the sensitivity of the parent strain to that of each E. coli deletion mutant for both PANI and P3ABA. Linear regression was used to fit a regression line through the data generating the best-fit value of the slope and intercept. An analysis of covariance (ANCOVA) was used to compare the regression lines from the parent strain and a 
mutant strain to determine if the effect of bacterial gene mutation on viable cell count posttreatment represented a statistically significant increase or decrease in sensitivity.

\section{EPR spectroscopy}

The Kruskal-Wallis test with Dunn's multiple comparison post-hoc test was used analyse difference between the free iron levels of $\mathrm{P} 3 \mathrm{ABA}$ treated, $\mathrm{H}_{2} \mathrm{O}_{2}$ treated, and untreated cells.

\section{Activity of PANI and P3ABA suspensions in aerobic and anaerobic conditions}

The Mann-Whitney test was used to analyse the difference between the aerobic and anaerobic MIC, and the aerobic and anaerobic MBC of PANI and P3ABA against $E$. coli 25922. The Mann-Whitney test was also used to compare the difference between the influence of the presence of oxygen on the activity of PANI and P3ABA against E. coli 25922.

\section{Catalase protection assay}

A repeated measures ANOVA was used to analyse the difference in cell viability of PANI treated, $\mathrm{P} 3 \mathrm{ABA}$ treated, and $\mathrm{H}_{2} \mathrm{O}_{2}$ treated cells in the presence and absence of exogenous catalase.

\section{Results and discussion}

\section{Sensitivity of $E$. coli deletion mutants to PANI and P3ABA suspensions}

Based on hypotheses generated from the transcriptomic analysis of $E$. coli cells challenged with an PPANI, the antimicrobial mechanism of PANI and P3ABA was investigated using selected deletion mutants from the Keio collection. Determination of the sensitivity of deletion mutants can be used to generate initial hypotheses pertaining to antimicrobial mechanism (Liu et al., 2010) or used to investigate existing mechanism hypotheses in a more targeted fashion (Feld, Knudsen \& Gram, 2012).

The mutants were selected based on the results from a transcriptomic analysis performed on cells challenged with an fPANI (Gizdavic-Nikolaidis et al., 2011). We hypothesised that E. coli mutants lacking oxidative stress response genes (E. coli $\Delta k a t G, E$. coli $\Delta k a t E$, E. coli $\Delta a h p C, E$. coli $\Delta \operatorname{sod} A, E$. coli $\Delta \operatorname{sodB}, E$. coli $\Delta \operatorname{sod} C$ ), genes involved in iron homeostasis (E. coli $\Delta f u r, E$. coli $\Delta$ tonB, E. coli $\Delta i s c S)$, genes involved in periplasmic stress responses (E. coli $\Delta s p y$, E. coli $\Delta a s r)$, and genes involved in DNA repair (E. coli $\Delta r e c A, E$. coli $\Delta n t h)$ would be more sensitive 
314 to PANI and P3ABA treatment. We also hypothesised that E. coli mutants lacking genes

315 involved in metabolism and respiration $(E$. coli $\Delta \operatorname{trx} C$, E. coli $\Delta$ grx A, E. coli $\Delta s d h B, E$. coli

$316 \triangle a t p E$ ) would be less sensitive to PANI and P3ABA treatment.

317 The parent strain (E. coli K12 BW25113) and mutants were challenged with $1 \%$ PANI or $1 \%$

318 P3ABA in suspension, and enumerated at selected time points (Tamae et al., 2008; Feld,

319 Knudsen \& Gram, 2012). The sensitivities of the deletion mutants relative to the parent strain

320 were determined (Table 1; raw data file) to infer mode of action and generate hypotheses to be

321 tested more rigorously. Details on statistical analysis are outlined in the final paragraph in the

322 'Sensitivity of E. coli deletion mutants to PANI and P3ABA suspensions' section and in the

323 'Statistical analysis' section in the materials and methods section. Bacteria with mutations in

324 genes involved in the defence against antimicrobial action will have increased sensitivity to

325 treatment while mutation of genes encoding antimicrobial targets will exhibit a decreased

326 sensitivity to treatment (Brazas \& Hancock, 2005; Tamae et al., 2008; Liu et al., 2010).

327 The E. coli deletion mutants were first tested in LB broth, a complex rich medium (Zhang \&

328 Greasham, 1999; Sezonov, Joseleau-Petit \& D’Ari, 2007). A subset of mutants was selected for

329 testing in a defined minimal medium with $0.4 \%$ succinate as the carbon source to focus on

330 antimicrobial effects in cells deriving energy almost exclusively from oxidative phosphorylation

331 (Cheng et al., 2006; Hards et al., 2015). The deletion mutants were selected for testing in

332 minimal media based on the hypotheses generated from the testing in rich media.

333 A role for oxidative stress from the production of $\mathrm{H}_{2} \mathrm{O}_{2}$ in the antibacterial mode of action of

334 PANI is supported by a) the supersensitivity of E. coli $\Delta k a t G$, which is unable to scavenge

335 endogenous $\mathrm{H}_{2} \mathrm{O}_{2}$ and respond to the oxidative stress, and b) the decreased sensitivity of E. coli

$336 \Delta a h p C$, which is missing the $\mathrm{H}_{2} \mathrm{O}_{2}$ scavenger utilised during normal growth leading to OxyR

337 activation before application of the PANI stress (Seaver \& Imlay, 2001; Mishra \& Imlay, 2012;

338 Zhang, Alfano \& Becker, 2015). Free iron can propagate $\mathrm{H}_{2} \mathrm{O}_{2}$ stress by participating in Fenton

339 reaction producing hydroxyl radicals (Imlay, 2008; Chiang \& Schellhorn, 2012). The reduced

340 sensitivity of $E$. coli $\triangle \operatorname{ton} B$, which has disrupted iron import, infers induction of an oxidative

341 stress state in PANI treated cells (Touati et al., 1995). Further evidence towards a $\mathrm{H}_{2} \mathrm{O}_{2}$ stress

342 based mechanism of action for PANI is derived from the greater sensitivity of the E. coli $\Delta i s c S$

343 mutant, which is unable to modify DNA for protection against oxidative stress (An et al., 2012). 
344 The supersensitivity of the Spy mutant suggests that at least some of the damage is occurring in 345 the periplasm (Raffa \& Raivio, 2002; Quan et al., 2011). There was no real effect of changing 346 the medium. Therefore, the PANI antimicrobial mechanism is hypothesised to involve $\mathrm{H}_{2} \mathrm{O}_{2}$

347 generation linked to the dysregulation of iron homeostasis, which eventuates in damage to 348 cellular biomolecules including periplasmic proteins.

349 The relative sensitivities of the selected E. coli deletion mutants to P3ABA treatment (Table 1; raw data file) suggested that P3ABA and PANI exert bactericidal activity through different mechanisms. Deletion of genes encoding $\mathrm{H}_{2} \mathrm{O}_{2}$ and superoxide scavenging enzymes, and proteins involved iron homeostasis did not change susceptibility to P3ABA treatment. P3ABA antimicrobial action appears to involve targeting of respiratory machinery, as reflected by the reduced sensitivity of $E$. coli $\triangle a t p E$ to $\mathrm{P} 3 \mathrm{ABA}$ treatment, which suggested that ATP synthase is targeted by P3ABA. Damage to ATP synthase would cause uncoupling of ATP synthesis from electron transport, which can result in futile cycling, and increased respiration (Noda et al., 2006; Hards et al., 2015). There was evidence to imply damaged proteins may accumulate in the periplasm following P3ABA exposure due to its proximity to the ETC and were inferred to happen based on the insensitivity of the Spy mutant (which was hypothesised to have upregulation of an additional extracytoplasmic stress response resulting in pre-adaption to P3ABA action) (Raivio \& Silhavy, 2001).

Statistically significant differences between the sensitivity of $E$. coli deletion mutants and the parent strain to P3ABA treatment were only detected in minimal media (Table 1). Increases in sensitivity were attributed to $E$. coli $\Delta g r x A, E$. coli $\Delta t o n B, E$. coli $\Delta i s c S, E$. coli $\Delta$ fur, E. coli $\Delta s d h B$, and E. coli $\Delta a s r$ treated with P3ABA suspension (Table 1) suggesting that perturbation of metabolism and iron homeostasis, oxidative stress, and acid stress is occurring in P3ABA treated cells.

The supersensitivity of the Grx1 mutant to P3ABA infers that this protein is involved in defence against P3ABA action. One of the functions of the glutaredoxin system, of which Grx1 is a member, is to scavenge hydroxyl radicals, a highly reactive ROS that causes biomolecule damage (Floyd \& Lewis, 1983; Starke, Chock \& Mieyal, 2003). Therefore, the increased sensitivity of $E$. coli $\triangle g r x A$ may reflect an inability to efficiently eliminate hydroxyl radicals produced during P3ABA antimicrobial action. 
374 The increased sensitivity of $E$. coli $\Delta$ fur may be due to the role Fur plays in survival in iron

375 limiting conditions, such as in minimal media (Seo et al., 2014). The effect of the absence of Fur

376 may be exacerbated in minimal media conditions compared to in rich media sensitising the cells

377 to the stress inducing actions of P3ABA. The increased sensitivity of E. coli $\Delta$ tonB, strain

378 lacking a gene involved in the uptake of iron (Moeck \& Coulton, 1998), supports the assertion

379 that P3ABA disrupts iron homeostasis

380 The increased sensitivities of $E$. coli $\Delta s d h B$ and $E$. coli $\Delta i s c S$ might reflect P3ABA targeting of 381 metabolism and respiration. E. coli $\Delta s d h B$ is lacking a gene encoding a subunit of SDH, which

382 couples the metabolic TCA pathway to respiration in the ETC (Tran et al., 2006). The increased

383 sensitivity of $E$. coli $\Delta s d h B$ to P3ABA suggests that loss of function of this important enzyme

384 undermines the ability of the bacteria to survive the bactericidal challenge. E. coli $\Delta i s c S$ is

385 missing a gene from the ISC pathway that functions in de novo synthesis of FeS clusters for

386 important metabolic and respiratory enzymes (Schwartz et al., 2000; Djaman, Outten \& Imlay,

387 2004). The resulting loss of function of the ISC pathway is only partially compensated by the

388 SUF pathway resulting in synthesis of only essential FeS clusters (Mettert \& Kiley, 2015). The

389 associated metabolic defects observed in E. coli $\Delta i s c S$ may sensitise the cells to P3ABA-

390 mediated damage of metabolic and respiratory machinery (Schwartz et al., 2000; Djaman, Outten

391 \& Imlay, 2004).

392 E. coli $\Delta a s r$ is missing a gene encoding Asr, a small basic periplasmic protein that promotes

393 survival under acid conditions (external $\mathrm{pH}$ of 4.5 or less) by putatively sequestering protons

394 (Seputiene et al., 2003). The supersensitive phenotype suggests that in these conditions Asr

395 confers resistance to the bactericidal action of P3ABA. The increased susceptibilities of mutants

396 missing genes involved in metabolism and iron homeostasis to P3ABA in minimal media

397 supports targeting of metabolic and respiratory machinery, which would be expected to elicit

398 greater responses for cells that have the increased metabolic demand of growth on minimal

399 media. The different responses seen in E. coli deletion mutants in rich and minimal media

400 highlight the advantages for antimicrobial testing in more than one type of media. Overall, the

401 antimicrobial susceptibility profiles for the E. coli deletion mutants in rich and minimal media

402 led to the refinement of hypotheses pertaining to the antimicrobial mechanism of PANI and

403 P3ABA. 
404 P3ABA treatment causes an increase in free iron in $\boldsymbol{E}$. coli

405 Based on the results and interpretation of the initial mechanism studies, it was hypothesised that PANI and P3ABA treatment would cause an increase in intracellular free iron in E. coli cells. An increase in free iron could be indicative of damage to iron-sulfur clusters of metabolic and respiratory enzymes as well as damage to mononuclear iron enzymes, possibly mediated through ROS (Jang \& Imlay, 2007; Anjem \& Imlay, 2012; Liu \& Imlay, 2013; Gu \& Imlay, 2013). The effect of $\mathrm{P} 3 \mathrm{ABA}$ on free iron levels in $E$. coli cells was examined using electron paramagnetic resonance (EPR) spectroscopy (Cammack \& Cooper, 1993; Woodmansee \& Imlay, 2002; Liu \& Imlay, 2013). EPR spectroscopy detects unpaired electrons, such as in ferric iron, permitting quantitation of free ferric iron levels (Cammack \& Cooper, 1993; Woodmansee \& Imlay, 2002). Since intracellular free iron can exist as $\mathrm{Fe}^{2+}$ or $\mathrm{Fe}^{3+}$, DF was added to treated cells as this iron chelator converts all free $\mathrm{Fe}^{2+}$ to the $\mathrm{Fe}^{3+}$ form permitting detection of the whole free iron pool (Liu, Bauer \& Imlay, 2011). The influence of PANI on free iron levels in E. coli could not be determined due to the insolubility of PANI.

$\mathrm{H}_{2} \mathrm{O}_{2}$ was used as a positive control in this experiment as it is known to cause an increase in unincorporated iron (Jang \& Imlay, 2007; Anjem \& Imlay, 2012). Following from this, antimicrobial activity involving oxidative stress should be signified by an increase in free iron levels in treated cells. Therefore, to determine if induction of oxidative stress occurs as part of P3ABA antimicrobial action, free iron levels were measured in E. coli cells sublethally treated with 0.5 \% P3ABA (Varghese et al., 2007; Liu \& Imlay, 2013; Gu \& Imlay, 2013).

A large peak representing intracellular $\mathrm{Fe}^{3+}$ was detected from $\mathrm{H}_{2} \mathrm{O}_{2}$ treated and $\mathrm{P} 3 \mathrm{ABA}$ cells, which were greater than that of untreated cells. This is indicative of oxidative damage to susceptible iron containing enzymes and the resulting release of iron. The free iron concentrations in $\mathrm{H}_{2} \mathrm{O}_{2}$ treated, $\mathrm{P} 3 \mathrm{ABA}$ treated, and untreated cells were determined from the spectra using the standard curve and are presented in Figure 2. The median free iron concentration in $\mathrm{H}_{2} \mathrm{O}_{2}$ treated cells $(90 \mu \mathrm{M})$ and P3ABA treated cells $(146 \mu \mathrm{M})$ were larger than the concentration in untreated cells $(22 \mu \mathrm{M})$. The difference between P3ABA treated cells and untreated cells was statistically significant (Kruskal-Wallis test, P value: less than 0.05, Dunn's multiple comparison test). These results suggest that P3ABA induces oxidative stress and the associated increase in unincorporated free iron in E. coli cells. 
434 E. coli $\Delta$ fur and E. coli $\Delta i s c S$ are missing pleiotropic genes that are involved not only in iron

435 homeostasis but also in other cellular functions including control of biofilm formation for the

436 former and sulfur trafficking for the latter (Ezraty et al., 2013; Seo et al., 2014). Therefore, a lack

437 of increased sensitivity of these mutants to P3ABA could be explained by changes to cellular

438 functions separate from control of iron homeostasis, which may influence susceptibility to 439 antimicrobial treatment (Jang \& Imlay, 2007). E. coli $\triangle$ tonB did not have altered sensitivity to 440 P3ABA relative to the parent strain, which suggests that the major iron import system does not 441 play a significant role in P3ABA mediated cell death but rather the increase in free iron may be 442 attributed to disruption of internal iron sources. Perturbation of internal iron management would 443 mean that prevention of iron import would not be protective against oxidative stress. A similar 444 situation was found for gyrase inhibitor mediated cell death (Dwyer et al., 2007).

445

446

447

448

449

450

451

452

453

454

455

456

457

458

459

460

461

462

463

Activity of PANI and P3ABA suspensions in aerobic and anaerobic conditions

The relative sensitivities of $E$. coli deletion mutants to PANI in LB broth (Table 1) support the hypothesis that the antimicrobial mechanism of PANI involves induction of $\mathrm{H}_{2} \mathrm{O}_{2}$ based oxidative stress and the perturbation of iron homeostasis. In contrast, the relative sensitivities of E. coli deletion mutants to P3ABA (Table 1) suggest targeting of metabolic and respiratory machinery, specifically ATP synthase, and induction of acid stress. The increase in unincorporated iron in P3ABA treated cells (Fig. 2) supports disruption of internal iron homeostasis, possibly through oxidative stress. Perturbation of respiratory machinery function may result in production of ROS as a downstream effect (Hards et al., 2015). This is supported by the localisation of electrons and oxygen to the ETC, and the identification of the sources of ROS in E. coli (Messner \& Imlay, 1999; Korshunov \& Imlay, 2006, 2010). Therefore, the activity of P3ABA may include production of ROS but at a lower extent than for PANI. The potential involvement of oxygen and its associated reactive species in the antimicrobial action of PANI and P3ABA warranted investigation.

To determine whether anaerobiosis was protective to the antimicrobial action of either PANI or P3ABA, the sensitivity of $E$. coli to these compounds in aerobic and anaerobic conditions was determined (Keren et al., 2013; Dwyer et al., 2014) as the MIC and MBC (Wiegand, Hilpert \& Hancock, 2008; Li et al., 2013). The media in which bacterial cells are grown can have important 
464 effects on the growth and physiological state of the cells and therefore may influence sensitivity 465 to inimical processes (Kram \& Finkel, 2015). E. coli cells growing in LB broth can generate 466 ATP through substrate level phosphorylation, oxidative phosphorylation, or fermentation 467 (Barton, 2005; Alteri, Smith \& Mobley, 2009; Farhana et al., 2010). The increased growth rate 468 and respiration of cells growing in LB broth means that they should be able to quickly respond to 469 an external stress by synthesising defence proteins as the building blocks required to do this are

470

471

472 found in the media (Tao et al., 1999). Minimal A is a defined medium that contains only the essential nutrients for growth (Zhang \& Greasham, 1999). Glycerol and succinate can function as the sole carbon and energy source for E. coli cells growing in minimal media (Tao et al., 1999). All building blocks needed for $E$. coli to grow, such as amino acids, must be synthesised from the carbon source (Tao et al., 1999). Energy can only be derived from these non-fermentable carbon sources mostly through oxidative phosphorylation; however, substrate level phosphorylation is relevant for glycerol as well (Jensen, Westerhoff \& Michelsen, 1993; Boogerd et al., 1998; Bekker et al., 2009).

\section{In aerobic conditions PANI is more active against $E$. coli 25922 in rich media and minimal media compared to anaerobic conditions}

In rich media, PANI demonstrated greater activity in aerobic conditions compared to anaerobic conditions (Fig. 3A). The aerobic MIC and MBC (0.25\% PANI) were less than the anaerobic MIC (3 \% PANI) and anaerobic MBC (8\% PANI). A similar trend was seen for the activity against E. coli 25922 in minimal A salts media with $0.7 \%$ glycerol and minimal A salts media with $0.4 \%$ succinate as a carbon source (Fig. 3B-3C). In minimal media with glycerol, the aerobic MIC and MBC (0.015625\% PANI) were lower than the anaerobic MIC (2\% PANI) and MBC (8 \% PANI). In minimal media with succinate, the aerobic MIC (0.015625\% PANI) and $\operatorname{MBC}(0.0625 \%$ PANI) were less than the anaerobic MIC (0.5\% PANI) and MBC (8\% PANI). For both minimal media types, the difference between the aerobic and anaerobic MIC and MBC of PANI against E. coli 25922 was statistically significant (Mann-Whitney test, P value: less than 0.05). The reduced sensitivity of $E$. coli 25922 to PANI treatment in anaerobic conditions infers that oxygen and its associated reactive species are involved in the mode of action of PANI. Aerobically, PANI had increased antimicrobial efficacy in minimal media compared to rich media as demonstrated by the lower MIC and $\mathrm{MBC}$ values in the former (Fig. 3A-3C). In rich media, the aerobic MIC and MBC (0.25\% PANI) was lower than in minimal media with 
495

496

497

498

499

500

501

502

503

504

505

506

507

508

509

510

511

512

513

514

515

516

517

518

519

520

521

522

523

524

525

glycerol (MIC and MBC $0.015625 \%$ PANI) and in minimal media with succinate (MIC $0.015625 \%$ PANI, MBC $0.0625 \%$ PANI). The increased sensitivity of E. coli 25922 in minimal media to the bactericidal activity of PANI was abolished in anaerobic conditions (MBC for all media, $8 \%$ PANI) (Fig. 3A-3C), which indicates that the E. coli 25922 cells were more susceptible to the antimicrobial action of PANI in both aerobic and low nutrient conditions. The increased susceptibility to PANI action in minimal media compared to LB broth may reflect the E. coli cells ability to respond efficiently to PANI induced stress in rich media as cells in minimal media must synthesise all building blocks, the enzymes for which are susceptible to oxidative damage.

The aerobic MBC of PANI against E. coli 25922 in minimal media with succinate as the carbon source $(0.0625 \%$ PANI) was higher than that in minimal media with glycerol as the carbon source $(0.015625 \%$ PANI). The difference in susceptibility to PANI in these conditions may be reflective of the metabolic state of E. coli growing on the particular carbon source. The succinate concentration used to support cell growth in this experiment was $\sim 15 \mathrm{mM}$. High concentrations of succinate (more than $8.8 \mathrm{mM}$ ) have been shown to reduce $\mathrm{H}_{2} \mathrm{O}_{2}$ formation by fumarate reductase, a flavin containing enzyme, by preventing autoxidation (Messner \& Imlay, 2002b).

The increased aerobic MBC of PANI against $E$. coli grown on succinate (compared to growth on glycerol) may be due to succinate somewhat reducing $\mathrm{H}_{2} \mathrm{O}_{2}$ production and following from this, susceptibility to PANI action. The lack of a difference in the bactericidal activity of PANI in the presence of succinate or glycerol in anaerobic conditions is supportive of this notion (Fig. 3A3B).

\section{In aerobic conditions $\mathrm{P3ABA}$ is more active against $E$. coli 25922 in rich media and} less active against $E$. coli 25922 in minimal media compared to anaerobic conditions The hypothesis that $E$. coli cells would exhibit greater sensitivity to P3ABA in energy poor conditions (i.e. low nutrient and no oxygen conditions) compared to energy rich conditions was mostly not supported, with the exception of the low anaerobic MIC $(0.0625 \%)$ in minimal media with succinate. It has been recently argued that ATP depletion following antimicrobial treatment does not cause bacterial cell death but rather delays the onset of killing (Cook et al., 2014a; Lobritz et al., 2015; Hards et al., 2015). It has been demonstrated that mycobacterial cells depleted of ATP do not loose viability (Frampton et al., 2012). The impact of ATP depletion on P3ABA action was indirectly examined by challenging $E$. coli cells grown on a non-glycolytic 
526 substrate, succinate, and E. coli cells grown on a glycolytic substrate, glycerol (Jensen et al.,

527 1995; Sorgen, 1999; Hards et al., 2015). The similar MIC and MBC values obtained for P3ABA

528 with challenge on succinate and on glycerol carbon sources (Fig. 3E-3F) suggest that the ability

529 to synthesise ATP by alternate methods does not prevent P3ABA bactericidal action. Consistent

530 with this, treatment of M. smegmatis with a novel antitubercular drug that targets ATP synthase,

531 bedaquiline, has been shown to result in downregulation of genes involved in glycolysis (Hards

532 et al., 2015). Therefore, antimicrobial mechanisms of P3ABA separate to the putative ATP

533 depletion may be involved in the bactericidal mode of action.

534 One important consideration for examining antimicrobial mechanism that involves targeting of

535 metabolism and respiration is that the metabolic state of the cell may influence how it responds

536 to bactericidal treatment (Lobritz et al., 2015). The bactericidal action of antimicrobial agents is

537 associated with increased respiration while bacteriostatic action is characterised by suppressed

538 cellular respiration (Lobritz et al., 2015). The bacteriostatic effect reduces ATP demand and is

539 often the dominant effect blocking bactericidal action (Lobritz et al., 2015). Following from this,

540 if cellular energy output is readily inhibited, such as in cells in energy poor conditions,

541 antimicrobial action may result in inhibition of growth rather than bactericidal killing (Lobritz et

542 al., 2015). Bacterial cells that are highly active may therefore be more susceptible to

543 antimicrobial exposure because of accelerated respiration.

544 It has been postulated that bedaquiline exerts lethal activity by uncoupling of respiration-driven

545 ATP synthesis causing increased respiration, loss of the proton gradient, and futile cycling

546 (Hards et al., 2015). The MBC of P3ABA in LB broth (Fig. 3D; aerobic $0.125 \%$ P3ABA,

547 anaerobic $0.375 \%$ P3ABA) was lower than that in minimal media with glycerol (Fig. 3E;

548 aerobic $1 \%$ P3ABA, anaerobic $0.5 \%$ P3ABA) and in minimal media with succinate (Fig. 3F;

549 aerobic $2 \%$ P3ABA, anaerobic $1 \%$ P3ABA). The greater activity of P3ABA in rich media

550 relative to minimal media may be due to the lower energy state of the E. coli cells in minimal

551 media. It is possible that the increased respiration and metabolic activity associated with $E$. coli

552 cells in LB broth would predispose the cells to the bactericidal action of P3ABA (resulting in

553 accelerated respiration and futile cycling) while the cells in minimal media may experience more

554 inhibitory action (Tao et al., 1999). Indeed, the MIC of bedaquiline against M. smegmatis

$555 \mathrm{MC}^{2} 155$ in LB broth $(0.01 \mu \mathrm{g} / \mathrm{ml})$ was lower compared to that in minimal media $(0.025 \mu \mathrm{g} / \mathrm{ml})$

556 (Hards et al., 2015). Succinate is a non-fermentable carbon source that necessitates ATP 
557 production to be carried out by the ETC (rather than by fermentation) compared to components

558 in LB broth. The notable difference in the anaerobic MIC and MBC of P3ABA in minimal media

559 with succinate (4 doubling dilutions) compared to that in other media ( 2 doubling dilutions)

560 may be reflective of the effective inhibition of cells by P3ABA in a very energy-poor

561 environment contributing to less effective bactericidal action (Fig. 3D-3F).

562 In this work, the hypothesis that the mode of action of P3ABA may eventuate in ROS production

563 has been proposed. To investigate this hypothesis, E. coli 25922 was challenged with P3ABA

564 suspensions in rich and minimal media in the presence and absence of oxygen. In rich media, the

565 MIC and MBC of P3ABA against E. coli 25922 were higher in anaerobic conditions (MIC 0.125

$566 \%$ P3ABA, MBC $0.375 \%$ P3ABA) compared to aerobic conditions (MIC $0.0625 \%$ P3ABA,

567 MBC $0.125 \%$ P3ABA) (Fig. 3D-3F). The greater MIC and MBC of P3ABA against E. coli

56825922 in anaerobic conditions relative to aerobic conditions were statistically significant (Mann-

569 Whitney test, $\mathrm{P}$ value: less than 0.05 ). The decreased activity of P3ABA in anaerobic conditions

570 suggests that in rich media the antimicrobial activity of P3ABA involves a small amount of ROS

571 production. Uncoupling activity, such as what is postulated to occur during P3ABA action,

572 causes futile cycling, which is associated with increased oxygen consumption and production of

573 ROS (Adolfsen \& Brynildsen, 2015; Hards et al., 2015). Therefore, the minor role of induction

574 of oxidative stress in P3ABA antimicrobial action may be due a downstream consequence of

575 uncoupling electron transport from ATP synthesis. P3ABA activity was less affected by

576 oxygenation compared to PANI activity, which implies that P3ABA acts through other more

577 important antimicrobial mechanisms.

578 The trend observed in rich media was distinct from that observed in minimal media. Reduced

579 activity of P3ABA was demonstrated when oxygen was present (Fig. 3E-3F). For minimal media

580 with glycerol, the aerobic MIC (0.25\% P3ABA) and MBC (1 \% P3ABA) were higher than the

581 anaerobic MIC (0.125 \% P3ABA) and MBC ( $0.5 \%$ P3ABA. Similarly in minimal media with

582 succinate, the aerobic MIC (0.5\% P3ABA) and MBC ( $\%$ P3ABA) were greater than the

583 anaerobic MIC (0.0625 \% P3ABA) and MBC (1 \% P3ABA). The difference between the MIC in

584 minimal media with succinate in aerobic and anaerobic conditions was statistically significant

585 (Mann-Whitney test, $\mathrm{P}$ value: less than 0.05 ) while all other differences observed for $E$. coli

58625922 in minimal media were not statistically significant (Mann-Whitney test, P value: more 
587 than 0.05$)$. These results suggest that induction of ROS-mediated stress is not occurring in E. coli 588 cells treated with P3ABA in minimal media.

589 PANI is less active in anaerobic conditions while P3ABA is less affected by the 590 absence of oxygen

591 The overall aim of the determination of the MIC and MBC of PANI and P3ABA against E. coli

592 in aerobic and anaerobic conditions was to examine the influence oxygen has on the activity of

593 these antimicrobial agents. A higher MBC in anaerobic conditions compared to aerobic

594 conditions is indicative of a reduction in bactericidal activity when no oxygen is present, which

595 would suggest that, taken with other evidence, the antimicrobial mechanism involves induction

596 of oxidative stress. The fold difference between the aerobic MBC and anaerobic MBC reflects

597 the extent oxygenation influences lethal activity. The difference in activity between aerobic and

598 anaerobic conditions is presented as a graph in Figure 4 with the fold change in MBC between

599 aerobic and anaerobic conditions on the $y$-axis and treatment on the $x$-axis. Greater activity in

600 aerobic conditions $\left(\mathrm{MBC} \mathrm{O}_{2}\right.$ less than $\left.\mathrm{MBC} \mathrm{AnO}_{2}\right)$ is represented by a number greater than 1

601 while greater activity in anaerobic conditions $\left(\mathrm{MBC} \mathrm{O}_{2}\right.$ more than $\left.\mathrm{MBC} \mathrm{AnO}_{2}\right)$ is represented by

602 a number less than 1 . No difference in activity between aerobic and anaerobic conditions (MBC

$603 \mathrm{O}_{2}=\mathrm{MBC} \mathrm{AnO}_{2}$ ) is represented by 1 .

604 The activity of PANI against E. coli 25922 in all media tested was decreased in anaerobic

605 conditions as indicated by a fold change of 32 and above (Fig. 4). In contrast to PANI, the

606 activity of P3ABA against these strains in LB broth was not affected as much by the presence

607 and absence of oxygen (Fig. 4). The difference between the influence of the presence of oxygen

608 on the activity of PANI compared to P3ABA against E. coli 25922 was statistically significant

609 (Mann-Whitney test, P value: less than 0.05). These results demonstrate that the antimicrobial

610 activity of PANI is more greatly influenced by the presence of oxygen compared to P3ABA,

611 which supports the hypothesis that PANI mediates induction of oxidative stress.

612 Effect of catalase on sensitivity of $E$. coli to PANI and P3ABA

613 The relative sensitivities of E. coli deletion mutants to PANI in LB broth (Table 1) support the

614 hypothesis that the antimicrobial mechanism of PANI involves increased production of $\mathrm{H}_{2} \mathrm{O}_{2}$ and

615 the perturbation of iron homeostasis, the result of which is endogenous oxidative stress. The

616 reduced efficacy of PANI suspension against E. coli 25922 in anaerobic, compared to aerobic, 
617 conditions (Fig. 4) supported this hypothesis. P3ABA is hypothesised to target respiratory 618 machinery, such as the ATP synthase, based on the greatly reduced sensitivity of E. coli $\Delta a t p E$ 619 and the loss of membrane potential measured in P3ABA treated E. coli cells (Robertson, 2012). 620 There is limited evidence that P3ABA treatment causes oxidative stress in $E$. coli grown in a rich 621 media (Fig. 3D-3F) but not in minimal media (Fig. 3E-3F). P3ABA antimicrobial action is less 622 affected by the presence of oxygen compared to PANI (Fig. 4).

623 The role of oxidative stress in PANI and P3ABA action was further investigated by determining 624 if exogenous catalase has a protective effect on E. coli 25922 cells challenged with PANI or 625 P3ABA suspension in rich media. $\mathrm{H}_{2} \mathrm{O}_{2}$ is membrane permeable and will equilibrise across the 626 cell membrane meaning that exogenous $\mathrm{H}_{2} \mathrm{O}_{2}$ levels in growth media will reflect the amount of 627 endogenous $\mathrm{H}_{2} \mathrm{O}_{2}$ (that has not been scavenged and is able to cause damage) (Ravindra Kumar \& 628 Imlay, 2013). Catalase, which scavenges $\mathrm{H}_{2} \mathrm{O}_{2}$ generating water and oxygen, was added to $E$. 629 coli 25922 cells exposed to PANI or P3ABA suspension in LB broth (Bhaumik et al., 1995). $630 \mathrm{H}_{2} \mathrm{O}_{2}$ was used as a positive control. Catalase is membrane impermeable and therefore can only 631 detoxify exogenous $\mathrm{H}_{2} \mathrm{O}_{2}$ (Bhaumik et al., 1995). Catalase detoxifying $\mathrm{H}_{2} \mathrm{O}_{2}$ in the growth media 632 would cause a decrease in intracellular $\mathrm{H}_{2} \mathrm{O}_{2}$ levels as it equilibrises across the cell membrane. 633 Therefore, exogenous catalase can protect against intracellular $\mathrm{H}_{2} \mathrm{O}_{2}$-mediated damage. A 634 protective effect by catalase (reflected in the viable cell count) is indicative of excess $\mathrm{H}_{2} \mathrm{O}_{2}$ 635 production in the exposed cells while no protective effect suggests that induction of $\mathrm{H}_{2} \mathrm{O}_{2}$ based 636 oxidative stress is not occurring.

637 It was hypothesised that E. coli cells would be less sensitive to PANI treatment in the presence of 638 catalase. $\mathrm{H}_{2} \mathrm{O}_{2}$ exposed cells dropped below the limit of detection while $\mathrm{H}_{2} \mathrm{O}_{2}$ exposed cells 639 incubated with catalase were present at a similar level to the untreated controls (Fig. 5A). PANI 640 treated cells showed a similar trend to the $\mathrm{H}_{2} \mathrm{O}_{2}$ treated cells. The treated cells incubated with 641 catalase were present at higher numbers (median cell count: $8.5 \times 10^{3} \mathrm{CFU} / \mathrm{ml}$ ) compared to 642 those incubated without catalase (median cell count: $1 \times 10^{2} \mathrm{CFU} / \mathrm{ml}$ ), suggesting that catalase 643 protected against PANI action by reducing exogenous (and therefore endogenous) $\mathrm{H}_{2} \mathrm{O}_{2}$ levels 644 (Fig. 5A). These results support PANI antimicrobial action involving production of $\mathrm{H}_{2} \mathrm{O}_{2}$ and 645 induction of oxidative stress. 
646 It was hypothesised that exogenous catalase would provide some protection to $E$. coli against 647 P3ABA antimicrobial action in rich media. E. coli cells treated with $\mathrm{H}_{2} \mathrm{O}_{2}$ were below the limit 648 of detection at the time points used while the presence of exogenous catalase prevented the 649 decrease in viable cell counts (Fig. 5B). In contrast to the trend seen for PANI, P3ABA treated 650 cells were knocked down independent of the presence of catalase. Similar viable cell counts were obtained for P3ABA alone (median cell count: $1.51 \times 10^{4} \mathrm{CFU} / \mathrm{ml}$ ) and P3ABA with catalase

$652\left(9.49 \times 10^{3} \mathrm{CFU} / \mathrm{ml}\right)\left(\right.$ Fig. 5B). These results indicate that production of excess $\mathrm{H}_{2} \mathrm{O}_{2}$ is not 653 occurring in P3ABA treated cells. Therefore, it is apparent that induction of $\mathrm{H}_{2} \mathrm{O}_{2}$-based oxidative stress does not have a major role in P3ABA antimicrobial action.

\section{Antimicrobial mechanism of PANI involves ROS production}

The sensitivity profile of PANI to Keio collection deletion mutants reinforced the hypothesis that antimicrobial action involves production of ROS. In rich media, the supersensitivity of $E$. coli $\Delta k a t G$, which is unable to scavenge exogenous $\mathrm{H}_{2} \mathrm{O}_{2}$, and the decreased sensitivity of $E$. coli $\triangle a h p C$, which is postulated to be preadapted to oxidative stress, supported this hypothesis (Table 1). There was also evidence to suggest perturbation of iron homeostasis in PANI treated cells in iron rich media as demonstrated by the reduced sensitivity of E. coli $\Delta$ tonB, which has reduced internal iron levels (Table 1). Iron homeostasis is intimately related to oxidative stress as free iron can propagate $\mathrm{H}_{2} \mathrm{O}_{2}$ stress by participating in Fenton reaction producing highly damaging hydroxyl radicals (Imlay, 2013). The increased susceptibility of E. coli $\Delta i s c S$ to PANI treatment (Table 1) may be due to an inability to modify DNA to protect against oxidation, suggesting involvement of oxidative stress (Xie et al., 2012; Imlay, 2013). There was also evidence of periplasmic stress as indicated by the supersensitivity of $E$. coli $\Delta$ spy to PANI suspension (Table 1).

The role of induction of oxidative stress in the mode of action of PANI was further investigated in $E$. coli 25922 by examining the activity of the antimicrobial agent in aerobic and anaerobic conditions. PANI was able to exert greater lethal activity when oxygen was present compared to anaerobic conditions in both rich and minimal media (Fig. 3A-3C). Endogenous ROS are generated at increased rates when the concentration of oxygen is high and cannot be produced when oxygen is absent (Seaver \& Imlay, 2004; Ravindra Kumar \& Imlay, 2013). Therefore, it was concluded that the greater activity of PANI in aerobic conditions reflects an oxidative stress 
676 mechanism involving increased production of ROS in treated bacterial cells, which may mediate

677 bactericidal action (Dwyer et al., 2014).

678 Furthermore, aerobic bactericidal activity of PANI against E. coli cells in minimal media with

679 glycerol as the carbon source was greater than that in minimal media with succinate (Fig. 3B-

680 3C). The difference in aerobic susceptibility to PANI could be indicative of the high

681 concentration of succinate $(\sim 15 \mathrm{mM})$ reducing endogenous $\mathrm{H}_{2} \mathrm{O}_{2}$ formation by preventing

682 fumarate reductase autoxidation and thus protecting against the putative PANI antimicrobial

683 action (Messner \& Imlay, 2002a). The antimicrobial activity of PANI is more affected by the

684 presence of oxygen compared to P3ABA, which supports the hypothesis that PANI mediates

685 induction of oxidative stress (Fig. 4).

686 Additional support for the hypothesis that PANI exerts bactericidal activity through facilitating

$687 \mathrm{H}_{2} \mathrm{O}_{2}$ production was derived from determining the protective effect of exogenous catalase.

688 Membrane impermeable catalase can detoxify endogenously produced $\mathrm{H}_{2} \mathrm{O}_{2}$ as it equilibrises

689 across the bacterial cell membrane (Ravindra Kumar \& Imlay, 2013). Therefore, exogenous

690 catalase can protect against intracellular $\mathrm{H}_{2} \mathrm{O}_{2}$-mediated damage. Catalase protected E. coli cells

691 against PANI bactericidal action (Fig. 5A), which is indicative of excess $\mathrm{H}_{2} \mathrm{O}_{2}$ production in the

692 exposed cells.

693 The mechanistic basis of PANI antimicrobial activity is hypothesised to be electrical

694 conductivity, which can mediate contact with the negatively charged bacterial cell surface

695 through electrostatic adherence and may be responsible for increased production of $\mathrm{H}_{2} \mathrm{O}_{2}$

696 (Gizdavic-Nikolaidis et al., 2011). Low concentrations of colloidal PANI have been associated

697 with biocompatibility and ROS scavenging abilities while higher concentrations have been

698 associated with antimicrobial activity, which demonstrates how the degree of electrical

699 conductivity can influence organism viability (Kucekova et al., 2014). PANI may perturb the

700 flow of electrons through the ETC (potentially mediated through electron acceptor capabilities),

701 which would result in accumulation of reducing equivalents leading to accelerated side reactions

702 with oxygen, generating ROS (Akhova \& Tkachenko, 2014). $\mathrm{H}_{2} \mathrm{O}_{2}$ is formed inside aerobically

703 growing $E$. coli is $10-15 \mu \mathrm{M}$ per second but is effectively scavenged by alkyl hydroperoxide

704 reductase and catalase (Imlay, 2013). If $\mathrm{H}_{2} \mathrm{O}_{2}$ levels increase past the threshold that can be

705 scavenged, then potentially lethal damage will occur. 
706 Many metabolic and respiratory enzymes are inactivated following oxidation by $\mathrm{H}_{2} \mathrm{O}_{2}$ within

707 minutes (Imlay, 2014). Susceptible enzymes have solvent exposed iron atoms and include those

708 containing [4Fe-4S $]^{2+}$ clusters (dehydratase enzymes, such as fumarase A and fumarase B from

709 the TCA cycle) and mononuclear iron enzymes (such as 3-deoxy-D-arabinoheptulosonate 7-

710 phosphate synthase involved in aromatic compound biosynthesis) (Jang \& Imlay, 2007; Sobota,

$711 \mathrm{Gu} \&$ Imlay, 2014). Oxidation of the iron atom promotes its dissociation from the enzyme,

712 causing loss of function, and an increase in free iron levels (Djaman, Outten \& Imlay, 2004).

713 Increased free iron released from oxidised enzymes can participate in Fenton reaction producing

714 hydroxyl radicals (Linley et al., 2012). The decreased sensitivity of E. coli $\Delta$ tonB (Table 1) to

715 PANI suspension supports the involvement of free iron in antimicrobial action.

716 Fur acts to control intracellular free iron levels by suppressing iron uptake and promoting iron

717 utilisation. Iron bound Fur can be oxidised by $\mathrm{H}_{2} \mathrm{O}_{2}$ inactivating the repressor (Varghese et al.,

718 2007). OxyR increases the expression of the fur gene in response to this; however, if the $\mathrm{H}_{2} \mathrm{O}_{2}$

719 levels are excessively high, most Fur would be inactivated leading to derepression of iron

720 acquisition systems and the deleterious import of more iron (Varghese et al., 2007). Inactivation

721 of Fur would release RyhB from Fur-mediated repression preventing synthesis of proteins

722 involved in iron utilisation and storage, including $s d h C D A B$ (Massé \& Gottesman, 2002; Massé,

723 Escorcia \& Gottesman, 2003; Massé \& Arguin, 2005). Thus, $\mathrm{H}_{2} \mathrm{O}_{2}$ can cause free iron levels to

724 increase due to targeting of oxidation susceptible iron containing enzymes and deregulation of

725 iron homeostasis involving uncontrolled iron import and a decreased capacity for incorporation

726 of iron into proteins. Upregulation of $r y h B$ expression was found to occur in response to fPANI

727 treatment, which supports de-repression of $r y h B$ expression due to oxidative inactivation of Fur

728 (Gizdavic-Nikolaidis et al., 2011). Further increase in intracellular free iron levels would result

729 in the production of more hydroxyl radicals and exacerbate the oxidative stress (Varghese et al., 730 2007).

731 Hydroxyl radicals are potent oxidants that can damage biomolecules, including DNA, proteins, 732 and lipids (Linley et al., 2012). It is postulated that the lethality of $\mathrm{H}_{2} \mathrm{O}_{2}$ is due to ROS-mediated 733 DNA double-strand breaks, particularly due to oxidation of guanine and thymine nucleotides

734 (Foti et al., 2012; Dwyer, Collins \& Walker, 2014). DNA repair systems function to detect and 735 repair damage; however, if these systems are overwhelmed then damage is not repaired (Imlay, 736 2013). Increased hydroxyl radicals derived from elevated free iron levels would result in 
737 increased rates of DNA damage (Linley et al., 2012). Thus, oxidative stress propagated by free

738 iron can cause lethal DNA damage.

739 The involvement of DNA in the antimicrobial mechanism of PANI was investigated by

740 challenging DNA repair mutant, E. coli $\Delta r e c A$. The decreased sensitivity of this mutant strain to

741 PANI may reflect mode- $2 \mathrm{H}_{2} \mathrm{O}_{2}$ mediated killing as opposed to mode-1 killing, which involves

742 DNA damage. Mode-2 killing occurs at higher $\mathrm{H}_{2} \mathrm{O}_{2}$ concentrations (more than $10 \mathrm{mM}$ ),

743 involves Fenton reaction and hydroxyl radicals, and reflects general damage to cellular

744 biomolecules (Imlay \& Linn, 1987; Martinez \& Kolter, 1997; Linley et al., 2012). Mode-2

745 killing does not require active growth, which is supported by the efficacious activity of PANI in

746 minimal media against E. coli (Fig. 3B-3C). This type of $\mathrm{H}_{2} \mathrm{O}_{2}$ killing is reduced in anoxic

747 conditions, which is consistent with the reduction in activity observed for PANI in anaerobic

748 conditions (Fig. 4) (Brandi et al., 1987; Linley et al., 2012). Therefore, PANI may mediate

749 production of a high concentration of $\mathrm{H}_{2} \mathrm{O}_{2}$ resulting in mode- 2 killing characterised by damage

750 to proteins and/or the cell membrane. Oxidation of amino acids in proteins can cause a range of

751 outcomes, from total degradation of the protein backbone to minor side-chain modification of

752 individual residues (Dean et al., 1997). Loss of essential protein function may cause bacterial cell 753 death.

754 There is a range of evidence to suggest that PANI mode of action includes production of $\mathrm{H}_{2} \mathrm{O}_{2}$

755 and the consequences of this; however, it is likely that there are additional mechanisms involved.

756 The lack of significant difference between the tested E. coli deletion mutants and the parent

757 strain challenged with PANI in minimal media suggests that other unidentified mechanisms are

758 involved in the antimicrobial action. Also, PANI activity was reduced in anaerobic conditions

759 compared to aerobic conditions (Fig. 3A-3C) but bactericidal activity was not completely

760 abolished. Thus, in anaerobic conditions there must be other unidentified mechanisms occurring

761 to cause cell death, the impact of which would likely vary relative to environmental conditions

762 (Dwyer et al., 2014).

\section{P3ABA acts as an uncoupler}

764 The sensitivity profile of $E$. coli deletion mutants challenged with P3ABA suspension inferred

765 that the antimicrobial mechanism involves perturbation of metabolism and iron homeostasis,

766 periplasmic stress, and acid stress. It should be noted that there may be additional antimicrobial 
767 mechanisms occurring that may have been missed due to testing of only a selection of deletion 768 mutants. There was evidence to suggest (Table 1) oxidative damage (E. coli $\triangle g r x A$ ) to metabolic 769 and respiratory enzymes (E. coli $\Delta s d h B$ and $E$. coli $\Delta i s c S$ ) occurs leading to perturbation of iron 770 homeostasis (E. coli $\Delta$ fur and E. coli $\Delta$ tonB) (Touati et al., 1995; Schwartz et al., 2000; Starke, 771 Chock \& Mieyal, 2003; Vlamis-Gardikas, 2008). The increased sensitivity of E. coli $\Delta a s r$ to P3ABA (Table 1) indicates that acid stress occurs during P3ABA antimicrobial action (Suziedeliené et al., 1999). The decreased sensitivity of as E. coli $\Delta$ spy in LB broth to P3ABA action (Table 1) probably reflected upregulation of an additional extracytoplasmic stress response (Raivio \& Silhavy, 2001), possibly from acid-induced protein misfolding. ATP synthase was identified as a potential target of P3ABA action as E. coli $\triangle a t p E$ in rich media had reduced sensitivity to $\mathrm{P} 3 \mathrm{ABA}$ treatment compared to the parent strain (Table 1). Bedaquiline, a novel antitubercular drug, is known to target ATP synthase, acting as an uncoupler (Sun et al., 2012; Koul et al., 2014; Hards et al., 2015). M. tuberculosis has been demonstrated to be sensitive to the antimicrobial action of $\mathrm{P} 3 \mathrm{ABA}$, which supports the ascertain that $\mathrm{P} 3 \mathrm{ABA}$ acts as an uncoupler (Robertson et al., 2016).

The involvement of perturbation of iron homeostasis in the antimicrobial mechanism of P3ABA was further investigated by using EPR spectroscopy to measure internal free iron levels in sublethally treated cells. An increase in intracellular free iron was detected in P3ABA treated cells in LB broth, similar to, but in a greater magnitude than $\mathrm{H}_{2} \mathrm{O}_{2}$ treatment (Fig. 2). Hydroxyl radicals are formed when unincorporated iron reacts with $\mathrm{H}_{2} \mathrm{O}_{2}$ during Fenton reaction (Imlay, 2013). The perturbation of iron homeostasis could promote oxidative stress, particularly the formation of hydroxyl radicals, which could explain the increased sensitivity of E. coli $\Delta$ grxA (Table 1). Furthermore, the lack of significant difference in sensitivity between the parent strain and $E$. coli $\triangle \operatorname{ton} B$ in LB broth suggests that the increase in intracellular free iron that occurs in P3ABA treated cells is derived from internal, rather than external, sources (Massé \& Arguin, 2005; Dwyer et al., 2007).

The activity of P3ABA in aerobic and anaerobic conditions against E. coli 25922 was examined to determine the involvement of ROS in the mechanism of P3ABA. E. coli 25922 was challenged with $\mathrm{P} 3 \mathrm{ABA}$ in both rich and minimal media, the latter with glycolytic and nonglycolytic carbon sources, allowing for inferences to be made relating to the effect of the energy state of the cell on the susceptibility to P3ABA action. Involvement of oxidative stress, indicated 
798 by greater activity in aerobic conditions, was only associated with $E$. coli challenged in rich 799 media and not in minimal media (Fig. 3D-3F). Production of ROS has been shown to be a 800 downstream effect of futile cycling caused by uncoupling activity (Adolfsen \& Brynildsen, 2015;

801 Hards et al., 2015). P3ABA was more active against E. coli in rich media compared to minimal 802 media in aerobic conditions, which is consistent with increased susceptibility to futile cycling 803 and bactericidal action associated with high respiration rates (Lobritz et al., 2015).

804 There was no difference in the activity of P3ABA when the E. coli cells were challenged in 805 minimal media with a glycolytic carbon source (glycerol) compared to a non-glycolytic carbon 806 source (succinate), from which ATP can only be made by oxidative phosphorylation, signifying 807 that the ability to synthesise ATP by alternate methods does not prevent P3ABA bactericidal 808 action (Jensen et al., 1995; Hards et al., 2015). A similar trend has been observed for $M$. 809 smegmatis treated with bedaquiline, an inhibitor of ATP synthase, supporting the hypothesis of 810 P3ABA acting as an uncoupler (Hards et al., 2015).

811 P3ABA is postulated to target, and probably damage, ATP synthase. This targeting is likely to be 812 due to the functionalisation of P3ABA as there was no evidence to suggest that PANI targets 813 ATP synthase. Damage to this biomolecule may permit $\mathrm{H}^{+}$ions to move from the periplasmic 814 space into the cytoplasm in an uncontrolled manner that is uncoupled from ATP synthesis (Hards 815 et al., 2015). The cell would continue to respire and the ETC would continue to pump $\mathrm{H}^{+}$into the 816 periplasm as electrons are transported along the chain, resulting in a futile proton cycle (Hards et 817 al., 2015). In response to the futile cycling, respiration and oxygen consumption would increase 818 potentially resulting in elevated production of ROS (Adolfsen \& Brynildsen, 2015; Belenky et 819 al., 2015).The effects of increased ROS production in a bacterial cell include dysregulation of 820 iron homoeostasis. The production of ROS is likely a downstream effect, which would explain 821 why it was not suggested by deletion mutant screening (Table 1) or by examining the potential 822 protective effect of exogenous catalase (Fig. 5B).

823 P3ABA mediated damaged to ATP synthase may cause acid stress as a downstream effect as 824 indicated by the susceptibility of E. coli $\triangle a s r$ to P3ABA (Table 1). ATP synthase and other 825 respiratory machinery components are implicated in the regulation of internal $\mathrm{pH}$, which implies 826 that damage to ATP synthase and perturbation of respiration would sensitise the cells to acid 827 stress (Sun et al., 2012). 
828 The exact events that directly lead to P3ABA-mediated cell death are not known. The

829 uncontrolled leakage of protons may cause dissipation of proton motive force (PMF; the sum of

830 the transmembrane $\mathrm{pH}$ gradient and the electrical potential), which is lethal to all living cells

831 (Rao et al., 2008; Hards et al., 2015). Supportive of this is the rapid loss of membrane potential

832 in E. coli that occurs following P3ABA exposure (Robertson, 2012). Collapse of PMF in E. coli

833 and S. aureus has been shown to trigger the process of autolysis (Brunskill \& Bayles, 1996;

834 Lamsa et al., 2012).

835 A proposed model for this, as described for Bacillus subtilis, involves repression of murein

836 hydrolase activity in cells with an intact PMF mediated by the localised reduction in $\mathrm{pH}$ within

837 the cell wall (Bayles, 2003; Rice \& Bayles, 2008; Tanouchi et al., 2013). Following dissipation

838 of membrane potential, the cell wall $\mathrm{pH}$ increases resulting in derepression of the murein

839 hydrolases (Lamsa et al., 2012). Deregulated murein hydrolases degrade peptidoglycan in the

840 bacterial cell wall, disrupting cell wall integrity and resulting in cell lysis (Lamsa et al., 2012). It

841 remains to be investigated whether autolysis occurs in P3ABA treated cells. Bactericidal action

842 of bedaquiline, which seems to act in a similar manner to P3ABA, does not involve dissipation

843 of PMF, attributed to the coupled exchange of other cations maintaining the electrical potential

844 (Hards et al., 2015). Elucidation of the lethal events in bedaquiline action is still ongoing and

845 may inform potential events in P3ABA bactericidal action (Cook et al., 2014b).

\section{Conclusion}

847 PANI in rich media is postulated to exert antimicrobial activity through increasing $\mathrm{H}_{2} \mathrm{O}_{2}$ levels

848 leading to oxidative stress characterised by perturbation of iron homeostasis, Fenton reaction, 849 and damage by hydroxyl radicals. P3ABA in minimal media is proposed to reduce bacterial cell 850 viability by targeting ATP synthase causing uncontrolled proton leak into the cytoplasm. The 851 resulting futile cycling may cause dissipation of PMF as well as acid stress as a downstream 852 effect. While it is apparent that the antimicrobial mechanism of P3ABA involves targeting of 853 ATP synthase, the events that occur following this are not fully characterised and require further 854 investigation.

\section{Acknowledgements}


856 The authors thank Sudip Ray, Adeline Le Cocq, Chris Wilcox and Walt Wheelwright for purified PANI and P3ABA.

858 The authors received research funding from the New Zealand Ministry of Business, Innovation and Employment (MBIE) for research programmes UOAX0812 and UOAX1410, and the University of Auckland's Vice Chancellors Strategic Development Fund, grant number 23563. The funders had no role in study design, data collection and analysis, decision to publish, or preparation of the manuscript.

\section{References}

864

Adler C., Corbalan NS., Peralta DR., Pomares MF., de Cristóbal RE., Vincent PA. 2014. The Alternative Role of Enterobactin as an Oxidative Stress Protector Allows Escherichia coli Colony Development. PLoS one 9:e84734. DOI: 10.1371/journal.pone.0084734.

Adolfsen KJ., Brynildsen MP. 2015. Futile cycling increases sensitivity toward oxidative stress in Escherichia coli. Metabolic Engineering 29:26-35. DOI: 10.1016/j.ymben.2015.02.006.

Akhova A V., Tkachenko AG. 2014. ATP/ADP alteration as a sign of the oxidative stress development in Escherichia coli cells under antibiotic treatment. FEMS microbiology letters 353:69-76. DOI: 10.1111/1574-6968.12405.

Alteri CJ., Smith SN., Mobley HLT. 2009. Fitness of Escherichia coli during urinary tract infection requires gluconeogenesis and the TCA cycle. PLoS pathogens 5:e1000448. DOI: 10.1371/journal.ppat.1000448.

An X., Xiong W., Yang Y., Li F., Zhou X., Wang Z., Deng Z., Liang J. 2012. A Novel Target of IscS in Escherichia coli: Participating in DNA Phosphorothioation. PLoS one 7:1-7. DOI: 10.1371/journal.pone.0051265.

Andrews SC., Robinson AK., Rodríguez-Quiñones F. 2003. Bacterial iron homeostasis. FEMS Microbiology Reviews 27:215-237. DOI: 10.1016/S0168-6445(03)00055-X.

Anjem A., Imlay JA. 2012. Mononuclear iron enzymes are primary targets of hydrogen peroxide stress. The Journal of biological chemistry 287:15544-56. DOI: 10.1074/jbc.M111.330365.

Anjem A., Varghese S., Imlay JA. 2009. Manganese import is a key element of the OxyR response to hydrogen peroxide in Escherichia coli. Molecular microbiology 72:844-58. DOI: 10.1111/j.13652958.2009.06699.x.

Baba T., Ara T., Hasegawa M., Takai Y., Okumura Y., Baba M., Datsenko KA., Tomita M., Wanner BL., Mori H. 2006. Construction of Escherichia coli K-12 in-frame, single-gene knockout mutants: the Keio collection. Molecular systems biology 2:1-11. DOI: 10.1038/msb4100050.

Bandyopadhyay S., Chandramouli K., Johnson MK. 2008. Iron-sulfur cluster biosynthesis. Biochemical Society transactions 36:1112-9. DOI: 10.1042/BST0361112.

Barton LL. 2005. Pathways of carbon flow. In: Structural and Functional Relationships in Prokaryotes. United States of America: Springer Science + Business Media, Inc, 529-601.

Bayles KW. 2003. Are the molecular strategies that control apoptosis conserved in bacteria? Trends in Microbiology 11:306-311. DOI: 10.1016/S0966-842X(03)00144-6. 
894

895

896

897

898

899

900

901

902

903

904

905

906

907

908

909

910

911

912

913

914

915

916

917

918

919

920

921

922

923

924

925

926

927

928

929

930

931

932

933

934

935

936

Bekker M., De Vries S., Ter Beek A., Hellingwerf KJ., Teixeira De Mattos MJ. 2009. Respiration of Escherichia coli can be fully uncoupled via the nonelectrogenic terminal cytochrome bd-II oxidase. Journal of Bacteriology 191:5510-5517. DOI: 10.1128/JB.00562-09.

Belenky P., Ye JD., Porter CBM., Cohen NR., Lobritz MA., Ferrante T., Jain S., Korry BJ., Schwarz EG., Walker GC., Collins JJ. 2015. Bactericidal Antibiotics Induce Toxic Metabolic Perturbations that Lead to Cellular Damage. Cell reports 13:968-80. DOI: 10.1016/j.celrep.2015.09.059.

Bhaumik G., Srivastava KK., Selvamurthy W., Purkayastha SS. 1995. The role of free radicals in cold injuries. International Journal of Biometeorology 38:171-175.

Blankenhorn D., Phillips J., Slonczewski JL. 1999. Acid- and base-induced proteins during aerobic and anaerobic growth of Escherichia coli revealed by two-dimensional gel electrophoresis. Journal of bacteriology 181:2209-16.

Boogerd FC., Boe L., Michelsen O., Jensen PR. 1998. atp mutants of Escherichia coli fail to grow on succinate due to a transport deficiency. Journal of Bacteriology 180:5855-5859.

Brandi G., Sestili P., Pedrini MA., Salvaggio L., Cattabeni F., Cantoni O. 1987. The effect of temperature or anoxia on Escherichia coli killing induced by hydrogen peroxide. Mutation research 190:237-40. DOI: 10.1016/0165-7992(87)90002-9.

Brazas MD., Hancock REW. 2005. Using microarray gene signatures to elucidate mechanisms of antibiotic action and resistance. Drug Discovery Today 10:1245-1252. DOI: 10.1016/S13596446(05)03566-X.

Brunskill EW., Bayles KW. 1996. Identification and molecular characterization of a putative regulatory locus that affects autolysis in Staphylococcus aureus. Journal of Bacteriology 178:611-618.

Cammack R., Cooper CE. 1993. Electron paramagnetic resonance spectroscopy of iron complexes and iron-containing proteins. Methods in enzymology 227:353-84.

Cheng V., Ma E., Zhao Z., Rothery RA., Weiner JH. 2006. The iron-sulfur clusters in Escherichia coli succinate dehydrogenase direct electron flow. The Journal of biological chemistry 281:27662-8. DOI: $10.1074 /$ jbc.M604900200.

Chiang SM., Schellhorn HE. 2012. Regulators of oxidative stress response genes in Escherichia coli and their functional conservation in bacteria. Archives of biochemistry and biophysics 525:161-9. DOI: 10.1016/j.abb.2012.02.007.

Cook GM., Greening C., Hards KJ., Berney M. 2014a. Advances in Bacterial Pathogen Biology. Elsevier Ltd. DOI: 10.1016/bs.ampbs.2014.08.001.

Cook GM., Hards K., Vilchèze C., Hartman T., Berney M. 2014b. Energetics of Respiration and Oxidative Phosphorylation in Mycobacteria. Microbiology spectrum 2:997-1003. DOI: 10.1128/microbiolspec.MGM2-0015-2013.

Dean RT., Fu S., Stocker R., Davies MJ. 1997. Biochemistry and pathology of radical-mediated protein oxidation. The Biochemical journal 324 ( Pt 1:1-18. DOI: 10.1042/bj3240001.

Dhand C., Das M., Datta M., Malhotra BD. 2011. Recent advances in polyaniline based biosensors. Biosensors \& bioelectronics 26:2811-21. DOI: 10.1016/j.bios.2010.10.017.

Dhivya C., Vandarkuzhali SAA., Radha N. 2014. Antimicrobial activities of nanostructured polyanilines doped with aromatic nitro compounds. Arabian Journal of Chemistry. DOI: 10.1016/j.arabjc.2015.12.005.

Djaman O., Outten FW., Imlay JA. 2004. Repair of oxidized iron-sulfur clusters in Escherichia coli. The Journal of biological chemistry 279:44590-9. DOI: 10.1074/jbc.M406487200.

Peer] reviewing PDF | (2018:02:25438:1:0:NEW 6 Jun 2018) 
937

938

939

940

941

942

943

944

945

946

947

948

949

950

951

952

953

954

955

956

957

958

959

960

961

962

963

964

965

966

967

968

969

970

971

972

973

974

975

976

977

978

979

980

Dwyer DJ., Belenky PA., Yang JH., MacDonald C., Martell JD., Takahashi N., Chan CTY., Lobritz MA., Braff D., Schwarz EG., Ye JD., Pati M., Vercruysse M., Ralifo PS., Allison KR., Khalil AS., Ting AY., Walker GC., Collins JJ. 2014. Antibiotics induce redox-related physiological alterations as part of their lethality. Proceedings of the National Academy of Sciences of the United States of America 111:E2100-9. DOI: 10.1073/pnas.1401876111.

Dwyer DJ., Collins JJ., Walker GC. 2014. Unraveling the Physiological Complexities of Antibiotic Lethality. Annual review of pharmacology and toxicology:1-20.

Dwyer DJ., Kohanski MA., Hayete B., Collins JJ. 2007. Gyrase inhibitors induce an oxidative damage cellular death pathway in Escherichia coli. Molecular systems biology 3:91. DOI: 10.1038/msb4100135.

Ezraty B., Vergnes A., Banzhaf M., Duverger Y., Huguenot A., Brochado AR., Su S-Y., Espinosa L., Loiseau L., Py B., Typas A., Barras F. 2013. Fe-S cluster biosynthesis controls uptake of aminoglycosides in a ROS-less death pathway. Science (New York, N.Y.) 340:1583-7. DOI: $10.1126 /$ science. 1238328 .

Farhana A., Guidry L., Srivastava A., Singh A., Hondalus MK., Steyn AJC. 2010. Reductive stress in microbes: Implications for understanding mycobacterium tuberculosis disease and persistence. Elsevier Ltd. DOI: 10.1016/B978-0-12-381045-8.00002-3.

Feld L., Knudsen GM., Gram L. 2012. Bactericidal antibiotics do not appear to cause oxidative stress in Listeria monocytogenes. Applied and environmental microbiology 78:4353-7. DOI: 10.1128/AEM.00324-12.

Floyd RA., Lewis CA. 1983. Hydroxyl free radical formation from hydrogen peroxide by ferrous ironnucleotide complexes. Biochemistry 22:2645-9.

Foti JJ., Devadoss B., Winkler JA., Collins JJ., Walker GC. 2012. Oxidation of the guanine nucleotide pool underlies cell death by bactericidal antibiotics. Science (New York, N.Y.) 336:315-9. DOI: 10.1126/science.1219192.

Frampton R., Aggio RBM., Villas-Bôas SG., Arcus VL., Cook GM. 2012. Toxin-antitoxin systems of Mycobacterium smegmatis are essential for cell survival. Journal of Biological Chemistry 287:5340-5356.

Genies EM., Boyle A., Lapkowski M., Tsintavis C. 1990. Polyaniline: A Historical Survey. Synthetic Metals 36:139-182.

Gizdavic-Nikolaidis MR., Bennett JR., Swift S., Easteal AJ., Ambrose M. 2011. Broad spectrum antimicrobial activity of functionalized polyanilines. Acta biomaterialia 7:4204-9. DOI: 10.1016/j.actbio.2011.07.018.

Gizdavic-Nikolaidis MR., Bennett JR., Zujovic Z., Swift S., Bowmaker GA. 2012. Characterization and antimicrobial efficacy of acetone extracted aniline oligomers. Synthetic Metals 162:1114-1119. DOI: 10.1016/j.synthmet.2012.04.031.

Gizdavic-Nikolaidis MR., Ray S., Bennett JR., Easteal AJ., Cooney RP. 2010a. Electrospun functionalized polyaniline copolymer-based nanofibers with potential application in tissue engineering. Macromolecular bioscience 10:1424-31. DOI: 10.1002/mabi.201000237.

Gizdavic-Nikolaidis MR., Zujovic ZD., Ray S., Easteal AJ., Bowmaker GA. 2010b. Chemical Synthesis and Characterization of Poly ( aniline- co -ethyl 3-aminobenzoate ) Copolymers. Journal of Polymer Science Part A: Polymer Chemistry 48:1339-1347. DOI: 10.1002/POLA.

Grass G., Rensing C., Solioz M. 2011. Metallic copper as an antimicrobial surface. Applied and environmental microbiology 77:1541-7. DOI: 10.1128/AEM.02766-10. 
981

982

983

984

985

986

987

988

989

990

991

992

993

994

995

996

997

998

999

1000

1001

1002

1003

1004

1005

1006

1007

1008

1009

1010

1011

1012

1013

1014

1015

1016

1017

1018

1019

1020

1021

1022

1023

Green J-BD., Fulghum T., Nordhaus M. 2011. Review of immobilized antimicrobial agents and methods for testing. Biointerphases 6:CL2-43. DOI: 10.1116/1.3645195.

Gu M., Imlay JA. 2011. The SoxRS response of Escherichia coli is directly activated by redox-cycling drugs rather than by superoxide. Molecular microbiology 79:1136-50. DOI: 10.1111/j.13652958.2010.07520.x.

Gu M., Imlay JA. 2013. Superoxide poisons mononuclear iron enzymes by causing mismetallation. Molecular microbiology 89:123-34. DOI: 10.1111/mmi.12263.

Hards K., Robson JR., Berney M., Shaw L., Bald D., Koul A., Andries K., Cook GM. 2015. Bactericidal mode of action of bedaquiline. The Journal of antimicrobial chemotherapy 70:2028-37. DOI: $10.1093 / \mathrm{jac} / \mathrm{dkv} 054$.

Imlay JA. 2008. Cellular defenses against superoxide and hydrogen peroxide. Annual review of biochemistry 77:755-76. DOI: 10.1146/annurev.biochem.77.061606.161055.

Imlay JA. 2013. The molecular mechanisms and physiological consequences of oxidative stress: lessons from a model bacterium. Nature reviews. Microbiology 11:443-54. DOI: 10.1038/nrmicro3032.

Imlay JA. 2014. The mismetallation of enzymes during oxidative stress. The Journal of biological chemistry 289:28121-8. DOI: 10.1074/jbc.R114.588814.

Imlay JA., Linn S. 1987. Mutagenesis and stress responses induced in Escherichia coli by hydrogen peroxide. Journal of bacteriology 169:2967-76.

Jang S., Imlay JA. 2007. Micromolar intracellular hydrogen peroxide disrupts metabolism by damaging iron-sulfur enzymes. The Journal of biological chemistry 282:929-37. DOI: 10.1074/jbc.M607646200.

Jensen PR., Loman L., Petra B., Vanderweijden C., Westerhoff H V. 1995. Energy Buffering of DNA Structure Fails when Escherichia coli Runs Out of Substrate. Journal of Bacteriology 177:3420 3426.

Jensen PR., Westerhoff H V., Michelsen O. 1993. Excess capacity of H(+)-ATPase and inverse respiratory control in Escherichia coli. The EMBO journal 12:1277-1282.

Keren I., Wu Y., Inocencio J., Mulcahy LR., Lewis K. 2013. Killing by bactericidal antibiotics does not depend on reactive oxygen species. Science (New York, N.Y.) 339:1213-6. DOI: $10.1126 /$ science. 1232688 .

Kim J., Copley SD. 2007. Why metabolic enzymes are essential or nonessential for growth of Escherichia coli K12 on glucose. Biochemistry 46:12501-11. DOI: 10.1021/bi7014629.

Kohanski MA., Dwyer DJ., Collins JJ. 2010. How antibiotics kill bacteria: from targets to networks. Nature reviews. Microbiology 8:423-35. DOI: 10.1038/nrmicro2333.

Korshunov S., Imlay JA. 2006. Detection and quantification of superoxide formed within the periplasm of Escherichia coli. Journal of Bacteriology 188:6326-6334. DOI: 10.1128/JB.00554-06.

Korshunov S., Imlay JA. 2010. Two sources of endogenous hydrogen peroxide in Escherichia coli. Molecular microbiology 75:1389-401. DOI: 10.1111/j.1365-2958.2010.07059.x.

Koul A., Vranckx L., Dhar N., Göhlmann HWH., Özdemir E., Neefs J-M., Schulz M., Lu P., Mørtz E., McKinney JD., Andries K., Bald D. 2014. Delayed bactericidal response of Mycobacterium tuberculosis to bedaquiline involves remodelling of bacterial metabolism. Nature communications 5:3369. DOI: $10.1038 /$ ncomms4369.

Kram KE., Finkel SE. 2015. Rich Medium Composition Affects Escherichia coli Survival, Glycation, and Mutation Frequency during Long-Term Batch Culture. Applied and environmental microbiology 
1024

1025

1026

1027

1028

1029

1030

1031

1032

1033

1034

1035

1036

1037

1038

1039

1040

1041

1042

1043

1044

1045

1046

1047

1048

1049

1050

1051

1052

1053

1054

1055

1056

1057

1058

1059

1060

1061

1062

1063

1064

1065

1066

81:4442-50. DOI: 10.1128/AEM.00722-15.

Kucekova Z., Humpolicek P., Kasparkova V., Perecko T., Lehocký M., Hauerlandová I., Sáha P., Stejskal J. 2014. Colloidal polyaniline dispersions: Antibacterial activity, cytotoxicity and neutrophil oxidative burst. Colloids and surfaces. B, Biointerfaces 116C:411-417. DOI: 10.1016/j.colsurfb.2014.01.027.

Kucekova Z., Kasparkova V., Humpolicek P., Sevcikova P., Stejskal J. 2013. Antibacterial properties of polyaniline-silver films. Chemical Papers 67:1103-1108. DOI: 10.2478/s11696-013-0385-x.

Lamsa A., Liu WT., Dorrestein PC., Pogliano K. 2012. The Bacillus subtilis cannibalism toxin SDP collapses the proton motive force and induces autolysis. Molecular Microbiology 84:486-500. DOI: 10.1111/j.1365-2958.2012.08038.x.

Li N., Luo M., Fu Y-J., Zu Y-G., Wang W., Zhang L., Yao L-P., Zhao C-J., Sun Y. 2013. Effect of corilagin on membrane permeability of Escherichia coli, Staphylococcus aureus and Candida albicans. Phytotherapy research : PTR 27:1517-23. DOI: 10.1002/ptr.4891.

Linley E., Denyer SP., McDonnell G., Simons C., Maillard J-Y. 2012. Use of hydrogen peroxide as a biocide: New consideration of its mechanisms of biocidal action. Journal of Antimicrobial Chemotherapy 67:1589-1596. DOI: 10.1093/jac/dks129.

Liu Y., Bauer SC., Imlay JA. 2011. The YaaA protein of the Escherichia coli OxyR regulon lessens hydrogen peroxide toxicity by diminishing the amount of intracellular unincorporated iron. Journal of bacteriology 193:2186-96. DOI: 10.1128/JB.00001-11.

Liu Y., Imlay JA. 2013. Cell death from antibiotics without the involvement of reactive oxygen species. Science (New York, N.Y.) 339:1210-3. DOI: 10.1126/science.1232751.

Liu A., Tran L., Becket E., Lee K., Chinn L., Park E., Tran K., Miller JH. 2010. Antibiotic sensitivity profiles determined with an Escherichia coli gene knockout collection: Generating an antibiotic bar code. Antimicrobial Agents and Chemotherapy 54:1393-1403. DOI: 10.1128/AAC.00906-09.

Lobritz MA., Belenky P., Porter CBM., Gutierrez A., Yang JH., Schwarz EG., Dwyer DJ., Khalil AS., Collins JJ. 2015. Antibiotic efficacy is linked to bacterial cellular respiration. Proceedings of the National Academy of Sciences of the United States of America 112:1509743112-. DOI: 10.1073/pnas.1509743112.

Macdiarmid AG. 2002. Synthetic metals: a novel role for organic polymers. Synthetic Metals 125:11-22. DOI: 10.1016/S0379-6779(01)00508-2.

Martínez-Gómez K., Flores N., Castañeda HM., Martínez-Batallar G., Hernández-Chávez G., Ramírez OT., Gosset G., Encarnación S., Bolivar F. 2012. New insights into Escherichia coli metabolism: carbon scavenging, acetate metabolism and carbon recycling responses during growth on glycerol. Microbial cell factories 11:46. DOI: 10.1186/1475-2859-11-46.

Martinez A., Kolter R. 1997. Protection of DNA during oxidative stress by the nonspecific DNA-binding protein Dps. Journal of bacteriology 179:5188-94.

Massé E., Arguin M. 2005. Ironing out the problem: new mechanisms of iron homeostasis. Trends in biochemical sciences 30:462-8. DOI: 10.1016/j.tibs.2005.06.005.

Massé E., Escorcia FE., Gottesman S. 2003. Coupled degradation of a small regulatory RNA and its mRNA targets in Escherichia coli. Genes \& development 17:2374-83. DOI: 10.1101/gad.1127103.

Massé E., Gottesman S. 2002. A small RNA regulates the expression of genes involved in iron metabolism in Escherichia coli. Proceedings of the National Academy of Sciences of the United States of America 99:4620-4625. DOI: 10.1073/pnas.032066599. 
1067

1068

1069

1070

1071

1072

1073

1074

1075

1076

1077

1078

1079

1080

1081

1082

1083

1084

1085

1086

1087

1088

1089

1090

1091

1092

1093

1094

1095

1096

1097

1098

1099

1100

1101

1102

1103

1104

1105

1106

1107

1108

1109

1110

Messner KR., Imlay JA. 1999. The identification of primary sites of superoxide and hydrogen peroxide formation in the aerobic respiratory chain. The Journal of biological chemistry 274:10119-28. DOI: 10.1074/jbc.274.15.10119.

Messner KR., Imlay JA. 2002a. Mechanism of superoxide and hydrogen peroxide formation by fumarate reductase, succinate dehydrogenase, and aspartate oxidase. Journal of Biological Chemistry 277:42563-42571. DOI: 10.1074/jbc.M204958200.

Messner KR., Imlay JA. 2002b. Mechanism of superoxide and hydrogen peroxide formation by fumarate reductase, succinate dehydrogenase, and aspartate oxidase. The Journal of biological chemistry 277:42563-71. DOI: 10.1074/jbc.M204958200.

Mettert EL., Kiley PJ. 2015. How Is Fe-S Cluster Formation Regulated? Annual review of microbiology 69:505-26. DOI: 10.1146/annurev-micro-091014-104457.

Mishra S., Imlay JA. 2012. Why do bacteria use so many enzymes to scavenge hydrogen peroxide? Archives of biochemistry and biophysics 525:145-60. DOI: 10.1016/j.abb.2012.04.014.

Moeck GS., Coulton JW. 1998. TonB-dependent iron acquisition: Mechanisms of siderophore-mediated active transport. Molecular Microbiology 28:675-681. DOI: 10.1046/j.1365-2958.1998.00817.x.

Noda S., Takezawa Y., Mizutani T., Asakura T., Nishiumi E., Onoe K., Wada M., Tomita F., Matsushita K., Yokota A. 2006. Alterations of cellular physiology in Escherichia coli in response to oxidative phosphorylation impaired by defective F1-ATPase. Journal of bacteriology 188:6869-76. DOI: 10.1128/JB.00452-06.

Prasad RGS V., Chaitanya KS V., Tejoram M., Basavaraju D., Rao KN., Kumar RR., Sreenivasan S., Phani AR. 2012. Antibacterial Properties of Nanofiber Structured Conducting Polyaniline Synthesized by Cost Effective Wet Chemical Process. 5:370-373.

Quan S., Koldewey P., Tapley T., Kirsch N., Ruane KM., Pfizenmaier J., Shi R., Hofmann S., Foit L., Ren G., Jakob U., Xu Z., Cygler M., Bardwell JCA. 2011. Genetic selection designed to stabilize proteins uncovers a chaperone called Spy. Nature structural \& molecular biology 18:262-9. DOI: 10.1038/nsmb.2016.

Raffa RG., Raivio TL. 2002. A third envelope stress signal transduction pathway in Escherichia coli. Molecular microbiology 45:1599-611. DOI: 10.1046/j.1365-2958.2002.03112.x.

Raivio TL., Leblanc SKD., Price NL. 2013. The Escherichia coli Cpx envelope stress response regulates genes of diverse function that impact antibiotic resistance and membrane integrity. Journal of Bacteriology 195:2755-2767. DOI: 10.1128/JB.00105-13.

Raivio TL., Silhavy TJ. 2001. Periplasmic stress and ECF sigma factors. Annual review of microbiology 55:591-624. DOI: 10.1146/annurev.micro.55.1.591.

Rao SPS., Alonso S., Rand L., Dick T., Pethe K. 2008. The protonmotive force is required for maintaining ATP homeostasis and viability of hypoxic, nonreplicating Mycobacterium tuberculosis. Proceedings of the National Academy of Sciences of the United States of America 105:11945-50. DOI: $10.1073 /$ pnas.0711697105.

Ravichandran R., Sundarrajan S., Venugopal JR., Mukherjee S., Ramakrishna S. 2010. Applications of conducting polymers and their issues in biomedical engineering. Journal of the Royal Society, Interface / the Royal Society 7 Suppl 5:S559-79. DOI: 10.1098/rsif.2010.0120.focus.

Ravindra Kumar S., Imlay JA. 2013. How Escherichia coli tolerates profuse hydrogen peroxide formation by a catabolic pathway. Journal of bacteriology 195:4569-79. DOI: 10.1128/JB.00737-13.

Rice KC., Bayles KW. 2008. Molecular control of bacterial death and lysis. Microbiology and molecular biology reviews : MMBR 72:85-109. DOI: 10.1128/MMBR.00030-07. 
1111

1112

1113

1114

1115

1116

1117

1118

1119

1120

1121

1122

1123

1124

1125

1126

1127

1128

1129

1130

1131

1132

1133

1134

1135

1136

1137

1138

1139

1140

1141

1142

1143

1144

1145

1146

1147

1148

1149

1150

1151

1152

1153

Robertson J. 2012. Studies toward an Understanding of the Antimicrobial Mechanism of Functionalised Polyanilines. Auckland: UoA.

Robertson J., Dalton J., Wiles S., Gizdavic-Nikolaidis M., Swift S. 2016. The tuberculocidal activity of polyaniline and functionalised polyanilines. PeerJ 4:e2795. DOI: 10.7717/peerj.2795.

Robertson J., Gizdavic-Nikolaidis M., Swift S. 2018. Investigation of Polyaniline and a Functionalised Derivative as Antimicrobial Additives to Create Contamination Resistant Surfaces. Materials 11:436. DOI: 10.3390/ma11030436.

Salavagione HJ., Acevedo DF., Miras MC., Motheo AJ., Barbero CA. 2004. Comparative study of 2amino and 3-aminobenzoic acid copolymerization with aniline synthesis and copolymer properties. Journal of Polymer Science Part A: Polymer Chemistry 42:5587-5599. DOI: 10.1002/pola.20409.

Schwartz C., Djaman O., Imlay JA., Kiley PJ. 2000. The cysteine desulfurase, IscS, has a major role in in vivo Fe-S cluster formation in Escherichia coli. Proceedings of the National Academy of Sciences of the United States of America 97:9009-14. DOI: 10.1073/pnas.160261497.

Seaver LC., Imlay JA. 2001. Alkyl hydroperoxide reductase is the primary scavenger of endogenous hydrogen peroxide in Escherichia coli. Journal of bacteriology 183:7173-81. DOI: 10.1128/JB.183.24.7173-7181.2001.

Seaver LC., Imlay JA. 2004. Are respiratory enzymes the primary sources of intracellular hydrogen peroxide? The Journal of biological chemistry 279:48742-50. DOI: 10.1074/jbc.M408754200.

Seo SW., Kim D., Latif H., O’Brien EJ., Szubin R., Palsson BO. 2014. Deciphering Fur transcriptional regulatory network highlights its complex role beyond iron metabolism in Escherichia coli. Nature communications 5:4910. DOI: 10.1038/ncomms5910.

Seputiene V., Motiejūnas D., Suziedelis K., Tomenius H., Normark S., Melefors Ö., Suziedeliene E. 2003. Molecular characterization of the acid-inducible asr gene of Escherichia coli and its role in acid stress response. Journal of bacteriology 185:2475-84. DOI: 10.1128/JB.185.8.2475.

Seshadri DT., Bhat N V. 2005. Use of polyaniline as an antimicrobial agent in textiles. Indian Journal of Fibre \& Textile Research 30:204-206.

Sezonov G., Joseleau-Petit D., D’Ari R. 2007. Escherichia coli physiology in Luria-Bertani broth. Journal of bacteriology 189:8746-9. DOI: 10.1128/JB.01368-07.

Shi N., Guo X., Jing H., Gong J., Sun C., Yang K. 2006. Antibacterial effect of the conducting polyaniline. Journal of Materials Science and Technology 22:289-290.

Sobota JM., Gu M., Imlay JA. 2014. Intracellular Hydrogen Peroxide and Superoxide Poison 3-Deoxy-DArabinoheptulosonate 7-Phosphate Synthase, the First Committed Enzyme in the Aromatic Biosynthetic Pathway of Escherichia coli. Journal of bacteriology 196:1980-91. DOI: 10.1128/JB.01573-14.

Sorgen PL. 1999. Lengthening the Second Stalk of F1F0 ATP Synthase in Escherichia coli. Journal of Biological Chemistry 274:36261-36266. DOI: 10.1074/jbc.274.51.36261.

Starke DW., Chock PB., Mieyal JJ. 2003. Glutathione-thiyl radical scavenging and transferase properties of human glutaredoxin (thioltransferase): Potential role in redox signal transduction. Journal of Biological Chemistry 278:14607-14613. DOI: 10.1074/jbc.M210434200.

Stejskal J., Sapurina I., Trchová M. 2010. Polyaniline nanostructures and the role of aniline oligomers in their formation. Progress in Polymer Science 35:1420-1481. DOI: 10.1016/j.progpolymsci.2010.07.006.

Su S-J., Kuramoto N. 2000. Synthesis of processable polyaniline complexed with anionic surfactant and 
1154

1155

1156

1157

1158

1159

1160

1161

1162

1163

1164

1165

1166

1167

1168

1169

1170

1171

1172

1173

1174

1175

1176

1177

1178

1179

1180

1181

1182

1183

1184

1185

1186

1187

1188

1189

1190

1191

1192

1193

1194

its conducting blends in aqueous and organic system. Synthetic Metals 108:121-126. DOI: 10.1016/S0379-6779(99)00185-X.

Sun Y., Fukamachi T., Saito H., Kobayashi H. 2012. Respiration and the $F_{1}$ Fo-ATPase enhance survival under acidic conditions in Escherichia coli. PLoS one 7:e52577. DOI: 10.1371/journal.pone.0052577.

Suziedeliené E., Suziedélis K., Garbenciūté V., Normark S. 1999. The acid-inducible asr gene in Escherichia coli: transcriptional control by the phoBR operon. Journal of bacteriology 181:2084-93.

Tamae C., Liu A., Kim K., Sitz D., Hong J., Becket E., Bui A., Solaimani P., Tran KP., Yang H., Miller JH. 2008. Determination of antibiotic hypersensitivity among 4,000 single-gene-knockout mutants of Escherichia coli. Journal of Bacteriology 190:5981-5988. DOI: 10.1128/JB.01982-07.

Tanouchi Y., Lee AJ., Meredith H., You L. 2013. Programmed cell death in bacteria and implications for antibiotic therapy. Trends in microbiology 21:265-70. DOI: 10.1016/j.tim.2013.04.001.

Tao H., Bausch C., Richmond C., Blattner FR., Conway T. 1999. Functional genomics: expression analysis of Escherichia coli growing on minimal and rich media. Journal of bacteriology 181:642540.

Touati D., Jacques M., Tardat B., Bouchard L., Despied S. 1995. Lethal oxidative damage and mutagenesis are generated by iron in delta fur mutants of Escherichia coli: protective role of superoxide dismutase. Journal of bacteriology 177:2305-14.

Tran QM., Rothery RA., Maklashina E., Cecchini G., Weiner JH. 2006. The quinone binding site in Escherichia coli succinate dehydrogenase is required for electron transfer to the heme b. The Journal of biological chemistry 281:32310-7. DOI: 10.1074/jbc.M607476200.

Varghese S., Wu A., Park S., Imlay KRC., Imlay JA. 2007. Submicromolar hydrogen peroxide disrupts the ability of Fur protein to control free-iron levels in Escherichia coli. Molecular microbiology 64:822-30. DOI: 10.1111/j.1365-2958.2007.05701.x.

Vlamis-Gardikas A. 2008. The multiple functions of the thiol-based electron flow pathways of Escherichia coli: Eternal concepts revisited. Biochimica et biophysica acta 1780:1170-200. DOI: 10.1016/j.bbagen.2008.03.013.

Wiegand I., Hilpert K., Hancock REW. 2008. Agar and broth dilution methods to determine the minimal inhibitory concentration (MIC) of antimicrobial substances. Nature protocols 3:163-75. DOI: 10.1038/nprot.2007.521.

Woodmansee AN., Imlay JA. 2002. Quantitation of intracellular free iron by electron paramagnetic resonance spectroscopy. Methods in enzymology 349:3-9.

Xie X., Liang J., Pu T., Xu F., Yao F., Yang Y., Zhao YL., You D., Zhou X., Deng Z., Wang Z. 2012. Phosphorothioate DNA as an antioxidant in bacteria. Nucleic Acids Research 40:9115-9124. DOI: 10.1093/nar/gks650.

Zhang L., Alfano JR., Becker DF. 2015. Proline metabolism increases katG expression and oxidative stress resistance in Escherichia coli. Journal of bacteriology 197:431-40. DOI: 10.1128/JB.0228214.

Zhang J., Greasham R. 1999. Chemically defined media for commercial fermentations. Applied Microbiology and Biotechnology 51:407-421. DOI: 10.1007/s002530051411. 


\section{Figure 1}

Structures of PANI and P3ABA.

PANI (A) consists of varying relative numbers of reduced and/or oxidised aniline subunits, which determine the average oxidation state (defined as $1-y)$. Reduced polymers $(y=1)$, called leucoemeraldine, have an average oxidation state of 0 . 'Half-oxidised' polymers ( $y=$ $0.5)$, called emeraldine, have an overall oxidation state of 0.5 . Oxidised polymers $(y=0)$, called pernigraniline, have an average oxidation state of 1. P3ABA (B) is a homopolymer of 3aminobenzoic acid (3-ABA). ABAs consist of an aniline benzene ring substituted with a carboxylic acid group (-COOH). 
A reduced unit oxidised unit

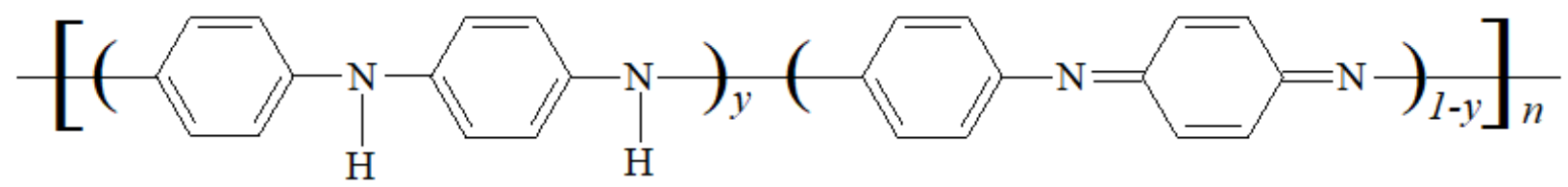

Legend :

$y=1 \quad$ Leucoemeraldine base (LEB)

$y=0.5 \quad$ Emeraldine base $(\mathrm{EB})$

$y=0 \quad$ Pernigraniline bas e (PNB)

\section{Emeraldine salt (ES)}

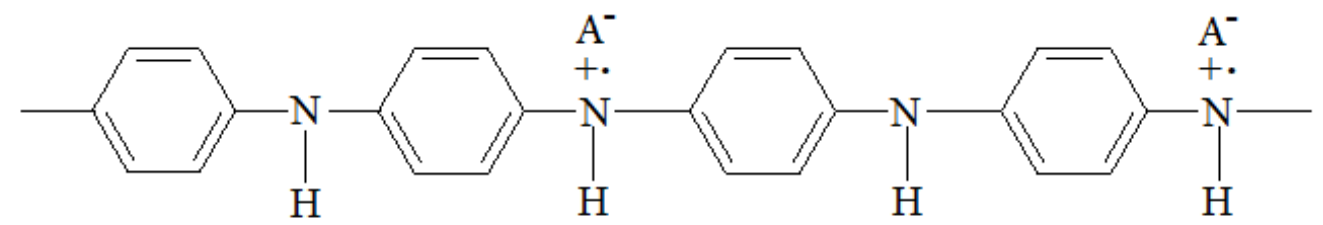

B

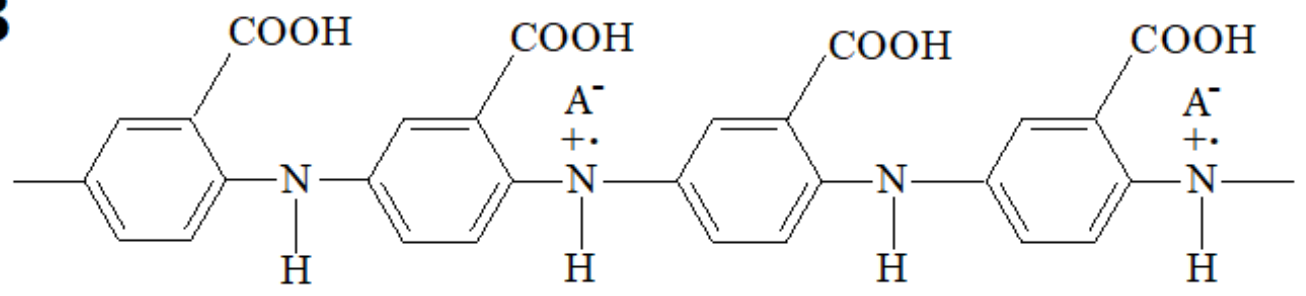




\section{Table $\mathbf{1}$ (on next page)}

Summary of the relative sensitivities of $E$. coli deletion mutants to $1 \%$ PANI and $1 \%$ P3ABA suspensions in LB broth and minimal A salts with $0.4 \%$ succinate.

Only deletion mutants that were significantly more or less sensitive to PANI or P3ABA treatment compared to the parent strain are presented. Blank spaces in the table represent non-significant differences for these strains. $E$. coli deletion mutants that were not significantly different for either treatment were not included in the table. The data the table was generated from is included in the raw data file. 
1 Table 1. Summary of the relative sensitivities of $E$. coli deletion mutants to $1 \%$ PANI and 1 $2 \%$ P3ABA suspensions in LB broth and minimal A salts with $0.4 \%$ succinate. Only deletion 3 mutants that were significantly more or less sensitive to PANI or P3ABA treatment compared to 4 the parent strain are presented. Blank spaces in the table represent non-significant differences for 5 these strains. E. coli deletion mutants that were not significantly different for either treatment 6 were not included in the table. The data the table was generated from is included in the raw data 7 file.

\begin{tabular}{|c|c|c|c|c|c|}
\hline & & \multicolumn{2}{|c|}{ LB broth } & \multicolumn{2}{|c|}{ Minimal media } \\
\hline \multicolumn{2}{|c|}{ Mutant strain } & PANI & P3ABA & PANI & P3ABA \\
\hline \multirow{3}{*}{$\begin{array}{l}\text { Oxidative stress } \\
\text { response }\end{array}$} & $\Delta k a t G$ & More & & & \\
\hline & $\Delta a h p C$ & Less & & & \\
\hline & $\Delta g r x A$ & & & & More \\
\hline \multirow{3}{*}{ Iron homeostasis } & $\Delta$ tonB & Less & & & More \\
\hline & $\Delta i s c S$ & More & & & More \\
\hline & $\Delta f u r$ & & & & More \\
\hline \multirow{2}{*}{$\begin{array}{l}\text { Metabolism and } \\
\text { respiration }\end{array}$} & $\Delta a t p E$ & & Less & & \\
\hline & $\Delta s d h B$ & & & & More \\
\hline \multirow{2}{*}{$\begin{array}{l}\text { Periplasmic stress } \\
\text { response }\end{array}$} & $\Delta \mathrm{s} p y$ & More & Less & & \\
\hline & $\Delta a s r$ & & & & More \\
\hline DNA repair & $\Delta r e c A$ & Less & & & \\
\hline
\end{tabular}

8 
Figure 2

Free iron concentration of $\mathrm{H}_{2} \mathrm{O}_{2}$ treated, P3ABA treated, and untreated $E$. coli samples.

Normalised EPR data showing the different free iron concentrations of $20 \mathrm{mM} \mathrm{H}_{2} \mathrm{O}_{2}$ treated, $0.5 \%$ P3ABA treated, and untreated E. coli cell samples. The treatment times for P3ABA and $\mathrm{H}_{2} \mathrm{O}_{2}$ were $30 \mathrm{~min}$ and $5 \mathrm{~min}$, respectively. Each data point represents a biological replicate with a line plotted at the median. Statistical significance is represented by * (Kruskal-Wallis test, $\mathrm{P}$ value: less than 0.05 , Dunn's multiple comparison post-hoc test).

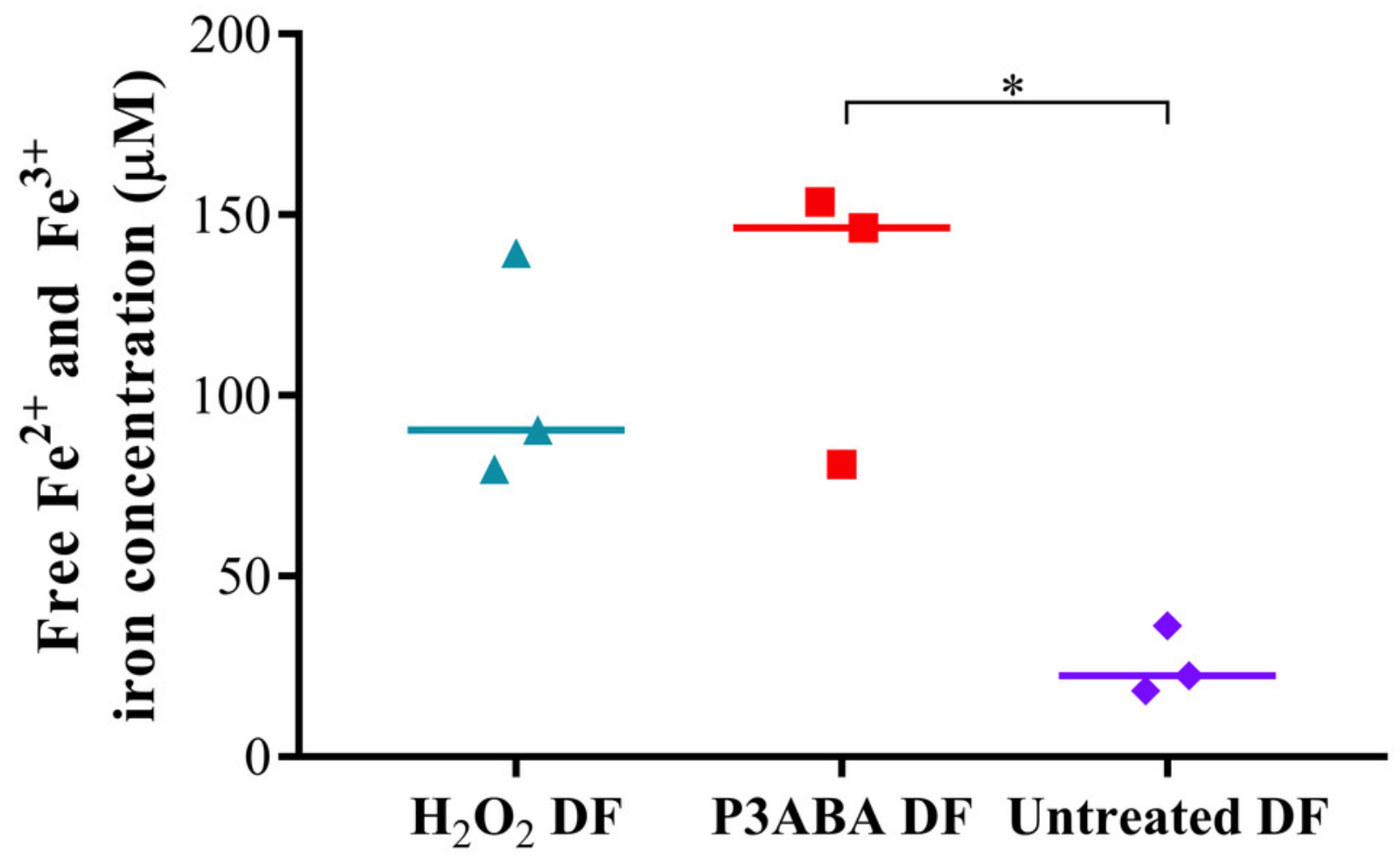




\section{Figure 3}

The effect of oxygen on the activity of PANI and P3ABA against E. coli 25922.

The MIC (circles) and MBC (squares) of PANI and P3ABA in aerobic $\left(\mathrm{O}_{2}\right.$, filled data points) and anaerobic $\left(\mathrm{AnO}_{2}\right.$, unfilled data points) conditions against E. coli 25922 are presented. The activity of PANI was determined in LB broth (A), minimal A salts with $0.7 \%$ glycerol (B), and minimal A salts with $0.4 \%$ succinate (C). The activity of P3ABA was determined in LB broth (D), minimal A salts with $0.7 \%$ glycerol (E), and minimal A salts with $0.4 \%$ succinate (F). Each data point represents a biological replicate with a line plotted at the median. Statistical significance is represented by * (Mann-Whitney test, P value: less than 0.05 ).
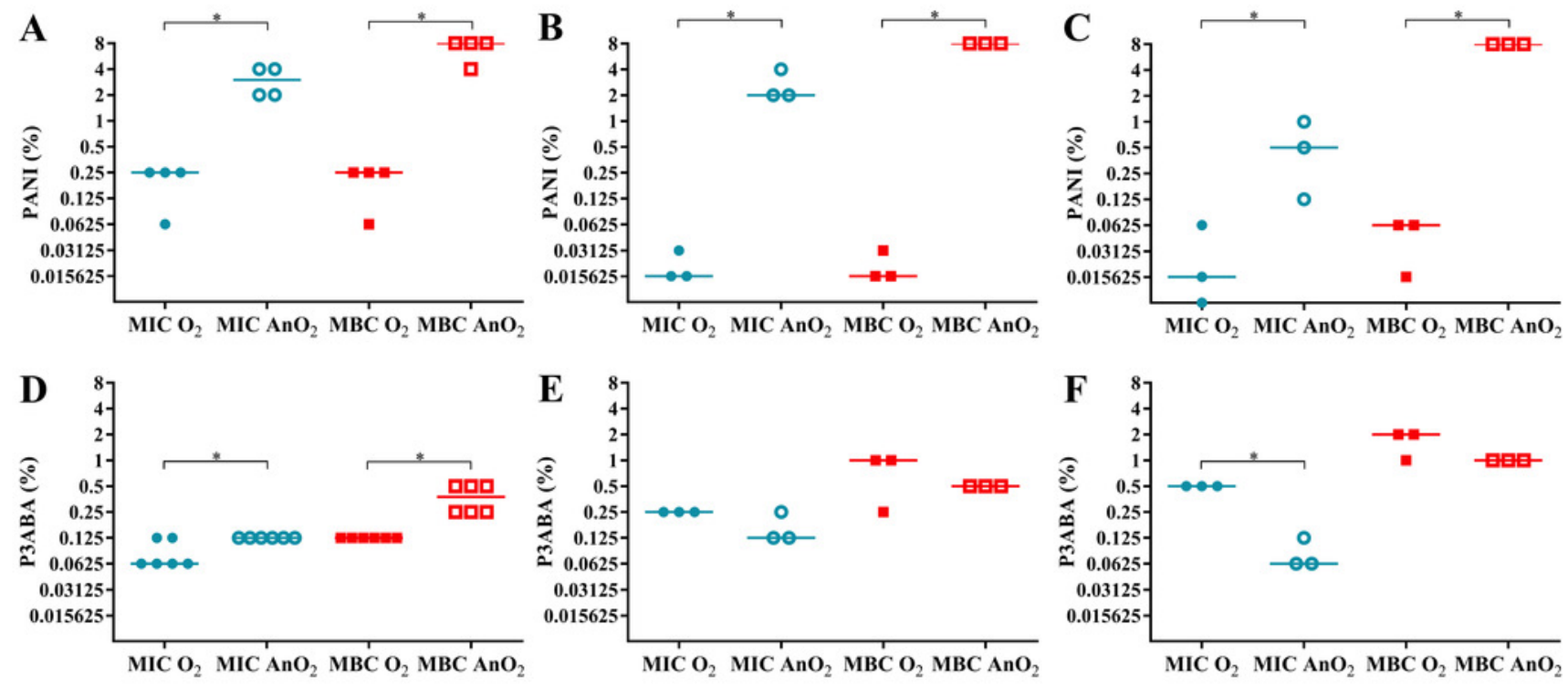


\section{Figure 4}

The difference between the MBC of PANI and P3ABA against E. coli 25922 in aerobic and anaerobic conditions.

The fold change in the MBC of PANI and P3ABA against E. coli 25922 in aerobic and anaerobic conditions. E. coli 25922 cells were challenged in LB broth (circles), minimal A salts with 0.7 $\%$ glycerol (squares) and minimal A salts with $0.4 \%$ succinate (triangles). The dotted line ( $y$ $=1$ ) represents no difference in the aerobic MBC and anaerobic MBC of PANI and P3ABA. Each data point represents a biological replicate with a line plotted at the median. Statistical significance is represented by * (Mann-Whitney test, $\mathrm{P}$ value: less than 0.05 ).

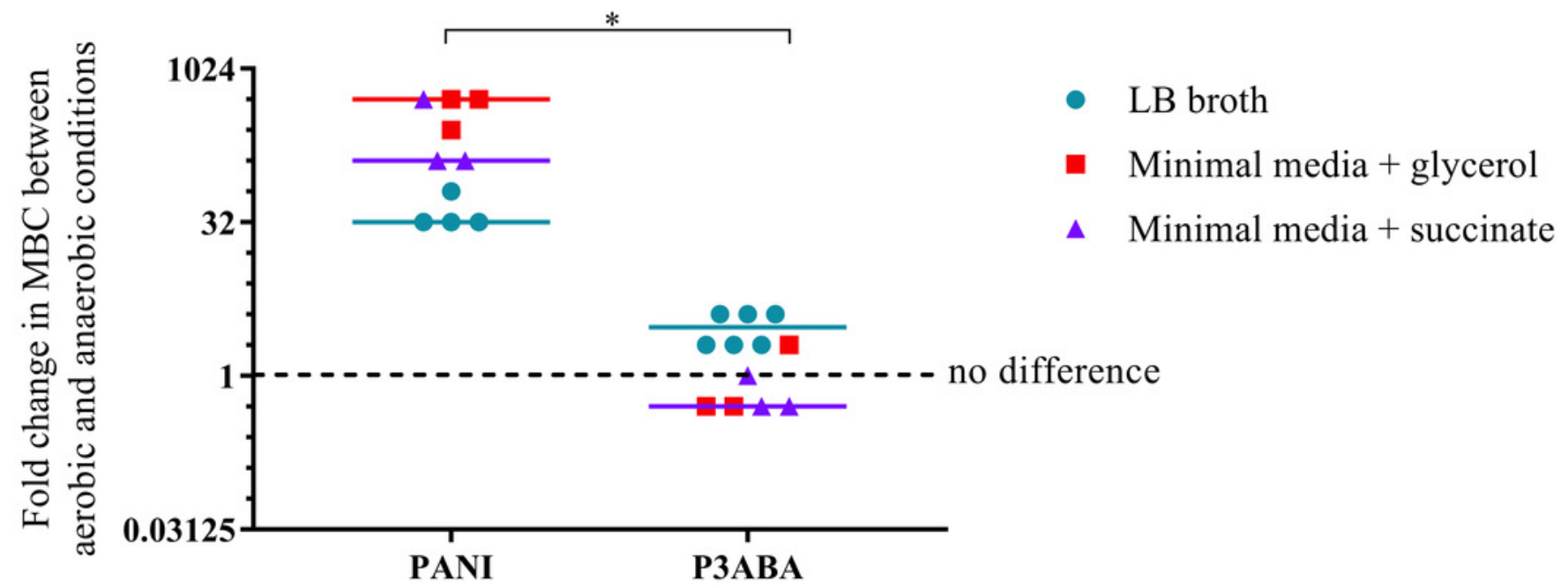




\section{Figure 5}

The effect of exogenous catalase on the sensitivity of $E$. coli 25922 to the antimicrobial action of PANI and P3ABA.

Cell viability assay of $\sim 10^{6} \mathrm{CFU} / \mathrm{ml}$ E. coli 25922 challenged with $2.5 \mathrm{mM} \mathrm{H}_{2} \mathrm{O}_{2}, 2 \%$ PANI suspension or $0.5 \%$ P3ABA suspension in LB broth. The treatment times for PANI and P3ABA were $2 \mathrm{~h}$ and $0.5 \mathrm{~h}$, respectively, with $\mathrm{H}_{2} \mathrm{O}_{2}$ treated and untreated cells enumerated at the same time. Each data point represents a biological replicate with a line plotted at the median. Statistical significance is represented by * (Repeated measures ANOVA, P value: less than 0.05). 

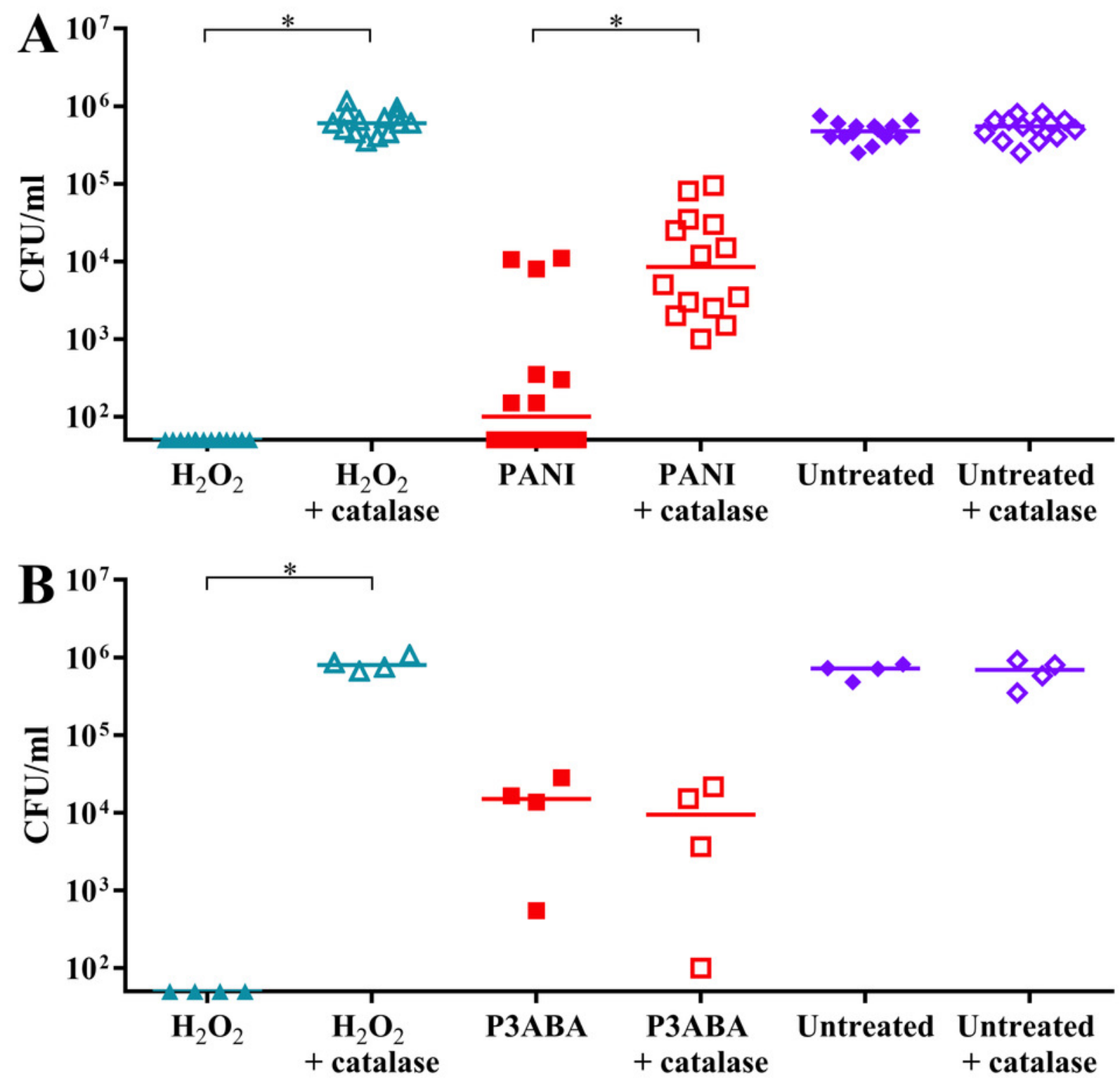